\title{
High-Angle-of-Attack Yawing Moment Asymmetry of the X-31 Aircraft from Flight Test
}

Brent R. Cobleigh

PRC Inc.

Edwards, California

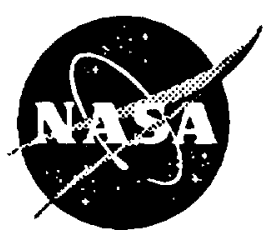

National Aeronautics and

Space Administration

Dryden Flight Research Center

Edwards, California 93523-0273 
?.. 


\section{TABLE OF CONTENTS}

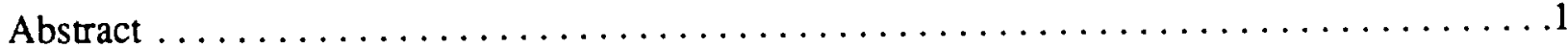

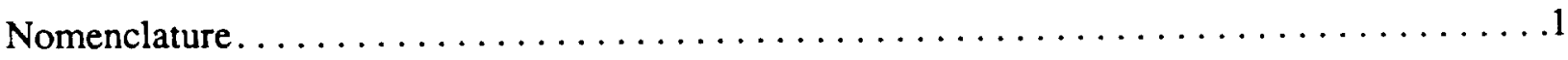

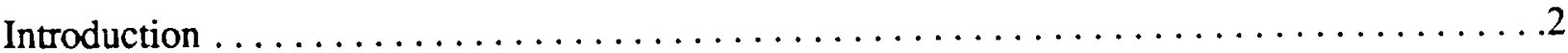

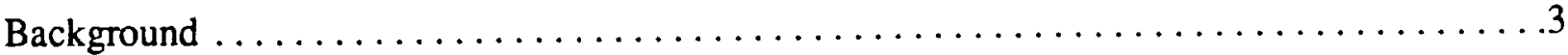

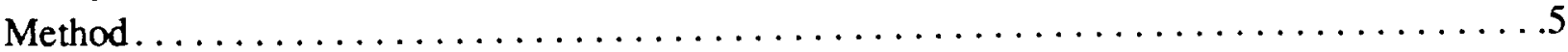

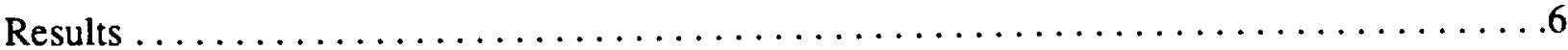

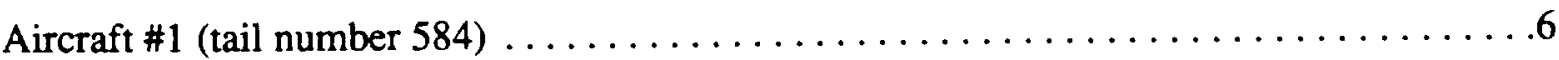

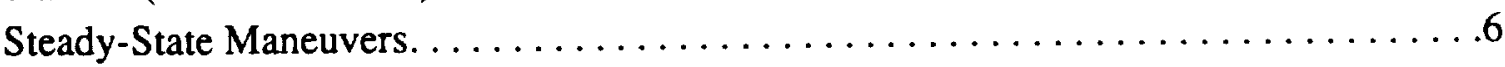

Symmetrical Dynamic Maneuvers. . . . . . . . . . . . . . . . . . . . . .

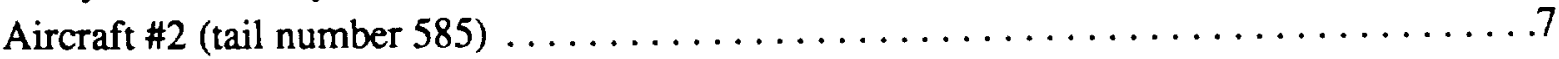

Steady-State Maneuvers. . . . . . . . . . . . . . . . . . . . . . . . . . . . . . .

Symmetrical Dynamic Maneuvers. . . . . . . . . . . . . . . . . . . . . . . . . .

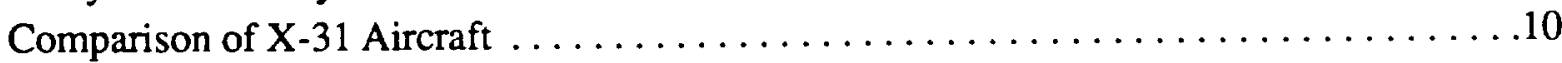

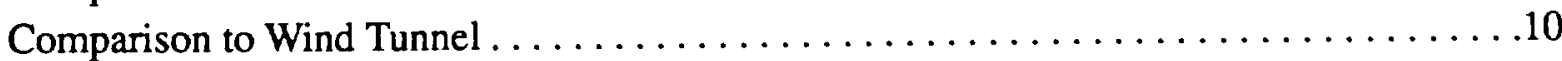

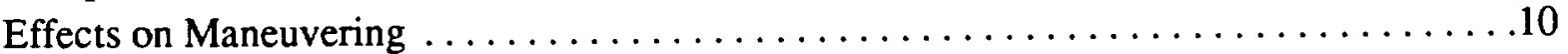

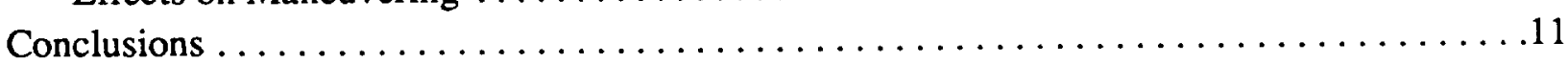

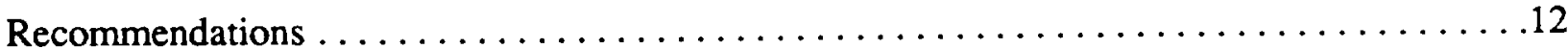

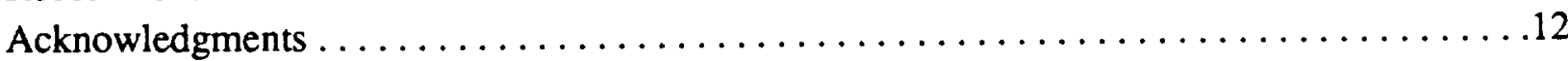

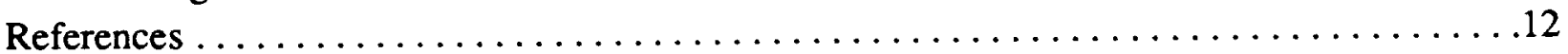


$\therefore \quad \therefore$ At 


\section{LIST OF FIGURES}

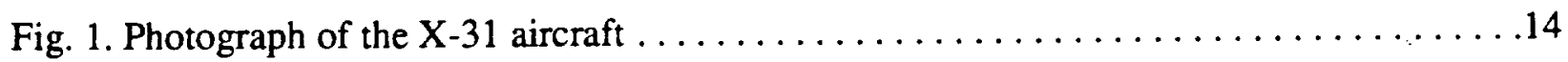

Fig. 2. Sketch of asymmetric forebody vortices on aircraft forebody $\ldots \ldots \ldots \ldots \ldots \ldots \ldots$

Fig. 3. Photograph of the forebody and noseboom transition strip. (EC 92 12083-6). . . . . 16

Fig. 4. Photograph of the 20 -in. strakes installed on the $X-31$ forebody . . . . . . . . . 16

Fig. 5. Side force asymmetry of a $3.0 \mathrm{l} / \mathrm{d}$ ogive with as a function of $\mathrm{AOA}$ for several roll

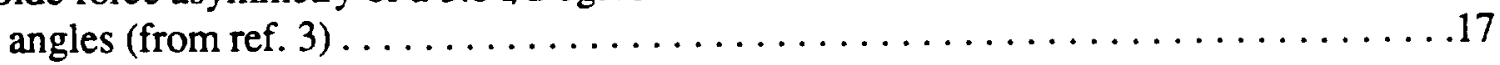

Fig. 6. Variation of side force coefficient on a $3.0 \mathrm{l} / \mathrm{d}$ ogive cylinder with model roll angle

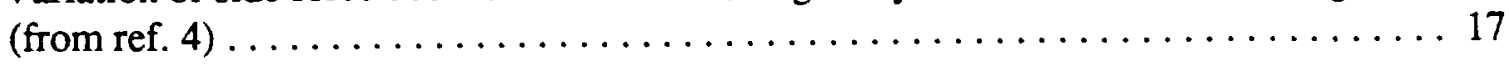

Fig. 7. Effect of Reynolds number on the side force of a $3.5 \mathrm{l} / \mathrm{d}$ ogive (from ref. 3) . . . . . . 18

Fig. 8. Variation of maximum side force with Reynolds number for several angles of

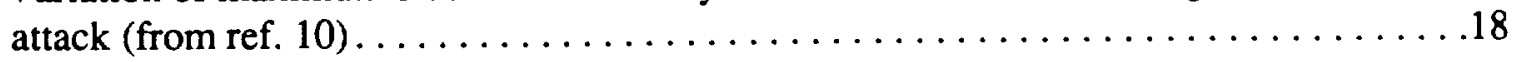

Fig. 9. Effect of nose bluntness on maximum side force asymmetry (from ref. 22) . . . . . 19

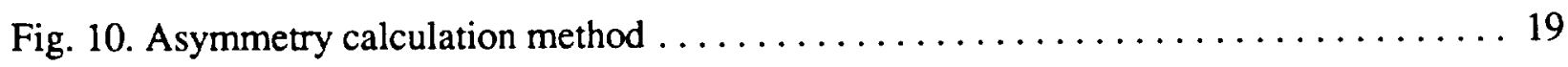

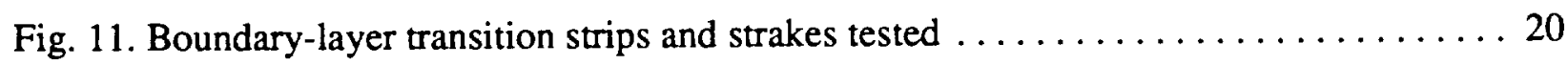

Fig. 12. Variation of yawing moment asymmetry with AOA for ship $1,1-\mathrm{g}$ maneuvers . .....21

Fig. 13. Maximum yawing moment coefficient with varying ship 1 configuration changes . . 21

Fig. 14. AOA range of asymmetric yawing moments with varying ship 1 configuration

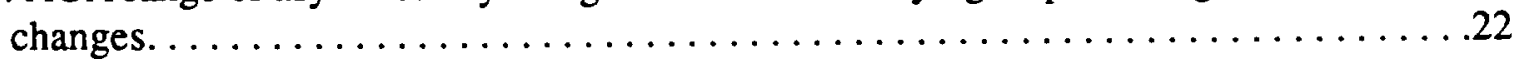

Fig. 15. Variation of yawing moment asymmetry with AOA for ship 1 dynamic maneuvers with the $\mathrm{S} 1$ strakes and noseboom transition strip. . . . . . . . . . . . . . . . 22

Fig. 16. Variation of yawing moment asymmetry with AOA for ship 1 dynamic maneuvers with the $\mathrm{S} 1$ strakes, forebody transition strip, and noseboom transition strip. . . . . . 23

Fig. 17. Variation of yawing moment asymmetry with AOA for ship 2 without strakes,

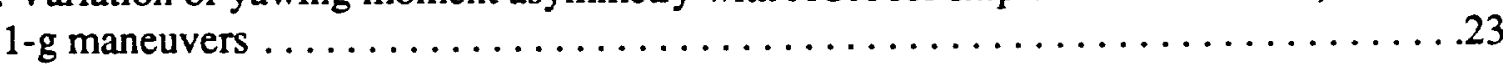

Fig. 18. Variation of drag coefficient with Reynolds number for a circular cylinder

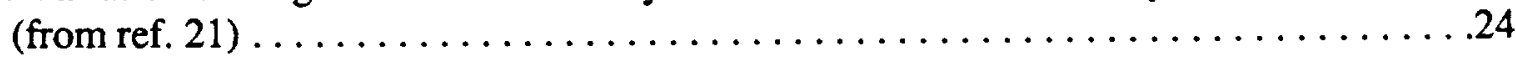

Fig. 19. Variation of yawing moment asymmetry with AOA for ship 2 with strakes, $1-\mathrm{g}$

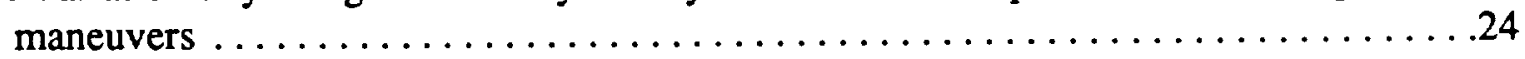

Fig. 20. Maximum yawing moment coefficient with varying ship 2 configuration changes $\ldots .25$

Fig. 21. AOA range of asymmetric yawing moments with varying ship 2 configuration

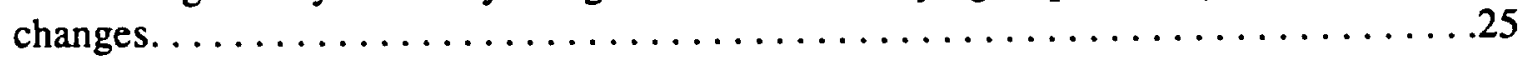

Fig. 22. Yawing moment asymmetry vs. AOA for the ship 2, flight 73 departure ........26 
Fig. 23. Variation of yawing moment asymmetry with AOA for ship 2 dynamic maneuvers

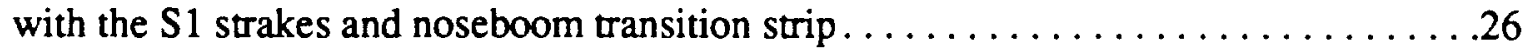

Fig. 24. Comparison of wind tunnel data to ship 1 flight results. $\ldots \ldots \ldots \ldots \ldots \ldots \ldots 27$

Fig. 25. Maximum yawing moment provided by thrust vectoring vs. calibrated airspeed . . . . 27

Fig. 26. Time history of a ship $2,50^{\circ}$ AOA left rolling maneuver $\ldots \ldots \ldots \ldots \ldots \ldots \ldots .28$ 


\begin{abstract}
Significant yawing moment asymmetries were encountered during the high-angle-of-attack envelope expansion of the two X-31 aircraft. These asymmetries led to position saturations of the thrust vector vanes and trailing-edge flaps during some of the dynamic stability axis rolling maneuvers at high angles of attack. This slowed the high-angle-of-attack envelope expansion and resulted in maneuver restrictions. Several aerodynamic modifications were made to the X-31 forebody with the goal of minimizing the asymmetry. A method for determining the yawing moment asymmetry from flight data was developed and an analysis of the various configuration changes completed. The baseline aircraft were found to have significant asymmetries above $45^{\circ}$ angle of attack with the largest asymmetry typically occurring around $60^{\circ}$-angle of attack. Applying symmetrical boundary-layer transition strips along the forebody sides increased the magnitude of the asymmetry and widened the angle-of-attack range over which the largest asymmetry acted. Installing longitudinal forebody strakes and rounding the sharp nose of the aircraft caused the yawing moment asymmetry magnitude to be reduced. The transition strips and strakes made the asymmetry characteristic of the aircraft more repeatable than the clean forebody configuration. Although no geometric differences between the aircraft were known, ship 2 consistently had larger yawing moment asymmetries than ship 1.
\end{abstract}

\title{
Nomenclature
}

$\begin{array}{ll}\mathrm{AB} & \text { afterburner } \\ \mathrm{AOA} & \text { angle of attack, deg } \\ \mathrm{Cd} & \text { drag force coefficient } \\ \mathrm{Cn} & \text { yawing moment coefficient } \\ \mathrm{Cn}_{0} & \text { yawing moment coefficient at zero sideslip } \\ \mathrm{Cy} & \text { side force coefficient } \\ \mathrm{Cy} \mathrm{y}_{0} & \text { side force coefficient at zero sideslip } \\ d & \text { body diameter } \\ \mathrm{EFM} & \text { Enhanced Fighter Maneuverability } \\ \mathrm{FB} & \text { forebody } \\ g & \text { aircraft normal load factor } \\ \mathrm{KCAS} & \text { knots calibrated airspeed } \\ L & \text { characteristic length } \\ l & \text { body length } \\ M & \text { Mach number } \\ \mathrm{NB} & \text { noseboom } \\ \bar{q} & \text { dynamic pressure, lb/ft }{ }^{2} \\ \mathrm{Re} & \text { Reynolds number, } \rho \mathrm{LV} / \mu \\ & \end{array}$




$\begin{array}{ll}\operatorname{Re}_{\mathrm{D}} & \text { Reynolds number based on forebody base diameter of } 3.2 \mathrm{ft} \\ \operatorname{Re}_{\mathrm{d}} & \text { Reynolds number based on noseboom diameter of } 3.5 \mathrm{in.} \\ \mathrm{I}_{\mathrm{b}} & \text { radius of forebody base } \\ \mathrm{I}_{\mathrm{n}} & \text { radius of nose tip } \\ \mathrm{S} 1 & 20 \text {-in. long by .60-in. wide strake } \\ \mathrm{S} 2 & 47 \text {-in. long by .60-in. wide strake } \\ V & \text { velocity } \\ \mu & \text { dynamic viscosity } \\ \rho & \text { density }\end{array}$

\section{Introduction}

The X-31 aircraft (Fig. 1) are being used in the Enhanced Fighter Maneuverability (EFM) research program, which is jointly funded by the Advanced Research Projects Agency (ARPA) and Germany's Federal Ministry of Defense (FMOD). The flight test portion of the program, which involves two aircraft, is being conducted by the National Aeronautics and Space Administration (NASA), the U.S. Navy, the U.S. Air Force, Rockwell International, and Deutsche Aerospace (DASA) at NASA's Dryden Flight Research Center, Edwards, CA. The goals of the flight program are to demonstrate EFM technologies, investigate close in combat exchange ratios, develop design requirements and database for future fighter aircraft, and to develop and validate low-cost prototype concepts.

Recently, analytical and simulation studies have shown that the appropriate use of high-angle-ofattack (AOA) maneuvering can result in a significant combat advantage. Unfortunately, the long slender forebody shapes of modern fighter aircraft make them susceptible to the body side-force problem. This side force is the result of surface pressure imbalances around the forebody of the aircraft caused by an asymmetric forebody boundary layer and vortex system. In this scenario, the boundary layer on each side of the forebody separates at different locations as shown in Fig. 2. At separation, corresponding vortex sheets are generated which roll up into an asymmetrically positioned vortex pair. The forces on the forebody are generated primarily by the boundary layer and to a lesser extent by the vortices, depending on their proximity to the forebody surface. Figure 2 shows a typical asymmetrical arrangement where the lower, more inboard vortex corresponds to a boundary layer which separated later and, conversely, the higher, more outboard vortex corresponds to the boundary layer which separated earlier. The suction generated by the more persistent boundary layer and the closer vortex combine to create a net force in their direction. Since the center of gravity of the aircraft is well aft of the forebody, a sizable yawing moment asymmetry develops.

During the 1-g high AOA envelope expansion of the X-31, both test aircraft exhibited significant, but different, yawing moment asymmetries at $0^{\circ}$ sideslip above $40^{\circ}$ AOA. Among the resulting aircraft responses were slow roll-offs and "lurches" (small, sharp heading changes). Although pilot compensation was attainable, up to 50 percent of roll stick deflection was required to counter the asymmetry. As a result, the full stick velocity vector roll rate of each aircraft was found to be faster in the direction of the asymmetry at a given angle of attack. To coordinate maneuvering 
with the yawing moment asymmetries, the control system had to increase the amount of control deflection required. In many cases, this increase resulted in a position saturation of one of the trailing-edge flaps or thrust vector paddles.

To reduce the asymmetry, transition grit strips were applied along the forebody (Fig. 3) to force boundary-layer transition at the same location on both sides of the forebody. This method had shown some promise in reducing high AOA yawing asymmetries during earlier tests on the F-18 High Alpha Research Vehicle (HARV). ${ }^{1}$ Transition strips were also installed along the noseboom with the hopes that a turbulent separation from the cylindrical cross-section would result in a reduced wake impinging on the forebody. These configuration changes improved the pilotreported handling qualities somewhat, however. the asymmetries were not eliminated.

Shortly into the high AOA, elevated-g phase of the envelope expansion, a departure from controlled flight occurred on ship 2 as the pilot was performing a $2-g$ split-S maneuver to $60^{\circ}$ AOA. Data analysis showed that a large unmodeled yawing moment, in excess of the available control power, had triggered the departure. Again the forebody vortex system was suspected to be the moment generator. An effort was begun to design and test forebody strakes with the hope that the strakes would improve the forebody vortex symmetry and eliminate any large-amplitude asymmetry changes, as was seen during the departure. A wind tunnel test ${ }^{2}$ was conducted in the NASA Langley Research Center's 30 - by $60-\mathrm{ft}$ wind tunnel to define the strake design and document any changes to the static stability characteristics. The tests showed that strakes running longitudinally along the waterline of the forebody from the nose tip reduced the model yawing moment asymmetry. The effectiveness of the strakes at reducing the asymmetry was not a function of the strake width, although the length of the strakes affected the amount of nose-up pitching moment. Two different length strake sets were flight tested and evaluated. A 20 -in. (Fig. 4) and a 46-in. long strake design were manufactured and flight tested in separate tests. Both strakes were .60 -in. wide.

This paper documents the yawing moment asymmetry characteristics of the various configurations during static and dynamic flight conditions.

\section{Background}

Many researchers have sought to understand the vortex asymmetry problem with wind tunnel studies of axisymmetric shapes, such as sharp cones, tangent ogives, and parabloids. Most of their efforts have been directed at answering three main questions. First, what are the mechanisms that cause asymmetric vortex patterns to form at high AOA on axisymmetric bodies? Second, how can the body be modified to eliminate or minimize the vortex asymmetry? Third, how can the vortices be manipulated to provide an exploitable high AOA yawing moment control device?

A striking illustration of the asymmetric problem was shown by Keener, Chapman, Cohen, and Taleghani ${ }^{3}$ by measuring the side force on an axisymmetric body at different roll angles at a given AOA. Since the model is axisymmetric, no lateral-directional forces or moments would be expected. Figure 5, however, shows that a large asymmetry develops on a $3.0 \mathrm{l} / \mathrm{d}$ fineness ratio ogive model starting at approximately $35^{\circ} \mathrm{AOA}$, and continues up past $70^{\circ} \mathrm{AOA}$. In addition, the sign of the asymmetry switches for a roll angle of $270^{\circ}$. Further tests by Lamont; ${ }^{4}$ Moskovitz, Hall, and DeJarnette; ${ }^{5}$ and Bridges and Hornung ${ }^{6}$ confirmed that the magnitude of the largest asymmetry does not change smoothly with changing roll angle. Instead, as an ogive cylinder is 
rolled through $360^{\circ}$, four changes in the sign of the asymmetry occur as shown in Fig. 6 . Thus, at high angles of attack, the vortex cores have bi-stable states. Other tests $3,5,7,8,9$ have shown that rotation of the nose tip alone produces the same result, suggesting that micro asymmetries near the model tip are significant in the asymmetry formation.

Reynolds number has also been shown to affect the asymmetry characteristic of slender bodies. ${ }^{3,4,7,10}$ Figure 7 shows that large changes in the magnitude and sign of the asymmetry can be effected by Reynolds number, however, the AOA range over which the aircraft is susceptible to asymmetries remains unchanged. The nature of the boundary-layer separation on the forebodywhether it laminar, transitional, or fully turbulent-is dependent on the Reynolds number. Above $30^{\circ} \mathrm{AOA}$, the maximum side force on a $3.5 \mathrm{l} / \mathrm{d}$ ogive is significantly larger for laminar and turbulent separation conditions than it is with transitional flow (Fig. 8).

The maximum asymmetry level has also been shown to be a function of the bluntness of the nose tip. ${ }^{9}$ Figure 9 illustrates that as the nose tip radius is increased, the maximum asymmetry is reduced. Eventually a minimum is reached, beyond which further blunting causes an increase in the asymmetry.

Realistic aircraft forebody shapes have consistently shown that the tendency for the vortices to become asymmetric is not limited to bodies of revolution. ${ }^{1,2,7,10,11}$ High AOA yawing moment asymmetries have been demonstrated on several full-scale aircraft including the F-18, F-20, and $X-29$. Since vertical tail effectiveness drops off rapidly with increasing AOA (caused by blanketing by the wing wake), the yawing moment asymmetry cannot be controlled by conventional methods. Thus, the need to reduce or eliminate the asymmetry is critical to obtain adequate handling qualities.

Several methods have been used to improve the asymmetry characteristics of high AOA aircraft. The traditional passive method of controlling the forebody vortices has been using longitudinal strakes near the apex on both sides of the forebody. Techniques that address the boundary-layer state have also gained attention. Since the nose tip appears to have a large influence on the asymmetry, several modifications to the tip have been studied as well.

Strakes have been shown to reduce or eliminate high AOA side force asymmetries on generic cone and ogive shapes, ${ }^{7,13}$ and on realistic aircraft forebodies. ${ }^{12,14,15,16}$ Cases of strakes not fully eliminating the asymmetry have also been found. ${ }^{11}$ The addition of strakes near the nose tip produces several beneficial effects on the forebody flowfield. First, the strakes tend to mask the presence of micro asymmetries on the model or aircraft. Second, the strakes fix the boundary separation line on the body, eliminating asymmetric boundary-layer separation as a cause of vortex asymmetry. Lastly, the strakes increase the vorticity (and thus the strength) of the primary vortex cores, making them less susceptible to other flowfields such as the canard or wing.

Boundary-layer transition or trip strips have also had limited success at reducing asymmetries. The purpose of transition strips is to ensure the boundary layer has transitioned to a turbulent state symmetrically on both sides of the forebody. Having similar boundary-layer states should lead to symmetrical separation and vortex formation. In limited tests on the HARV, ${ }^{1}$ a symmetrically applied transition grit strip eliminated the asymmetric pressure distribution that was caused by asymmetric vortices. Rao ${ }^{17}$ used research on cylinders to devise a helical trip strip. The helical trip strip disrupts the formation of the primary vortices by causing nonuniform crossflow separation. Eliminating the vortices removes the asymmetry source. 
Modi and Stewart ${ }^{18}$ tested several nose tip modifications to alleviate high AOA side forces. Installing a noseboom at the tip of a body of rotation reduced the maximum side force by as much as 50 percent for nosebooms greater than 8 percent of the model length. An increase in the maximum side force was measured for shorter nosebooms. Replacing the forward portion of the nose cone with a porous tip further reduced the maximum side force. Spinning the tip of the model at and above 100 revolutions per minute was also found to reduce the maximum side force up to 71 percent. The direction of the residual asymmetry was correlated with the direction of the tip rotation.

Excellent reviews of the high AOA vortex asymmetry problem have been compiled by Hunt ${ }^{19}$ and Ericsson. ${ }^{20}$

\section{Method}

To better understand and quantify the high-angle-of-attack yawing moment asymmetry characteristic of the X-31 aircraft, a method was developed to calculate time histories of the asymmetric forces and moments on the aircraft from flight data. A block diagram of the method is shown in Fig. 10. The flight measured yawing moment was computed by substituting the measured variables into the rigid body equation of motion. The flight measured yawing moment was then subtracted from that predicted from the simulation aerodynamic and thrust databases to calculate the missing, unmodeled components. By restricting data analysis to symmetrical maneuvers in which sideslip, roll rate, and yaw rate were small, the cause of the missing aerodynamic yawing moment was narrowed to three main sources: (1) errors in the thrust vectoring model, (2) errors in the control effectiveness model, and (3) aerodynamic asymmetries. Since the control effectiveness database was verified and updated with parameter identification results and the thrust model errors were not expected to be a strong function of angle of attack, any changes in the missing components with increases in AOA were attributed to aerodynamic asymmetries. An analysis of multiple decelerations, pull-ups, and split-S maneuvers with the same aircraft configuration resulted in a "fingerprint" of the asymmetry characteristic for a given configuration at a given flight condition.

The X-31 control laws were designed to allow the pilot to command AOA with the pitch stick, stability axis roll rate with the roll stick, and sideslip with the rudder pedals. From 30 to $50^{\circ} \mathrm{AOA}$, the sideslip commands were faded to zero. Two control law features worked to make the maneuvers nearly independent of pilot technique. The first of these was an AOA limiter. The AOA limiter allowed the pilot to set the maximum AOA command that the control laws would generate for a specific maneuver. This permitted the pilot to pull the stick aft of the target command, resulting in an AOA command that stopped at the limiter setting. The second control law feature was a $25 \mathrm{deg} / \mathrm{sec}$ rate limiter on the AOA command. Thus, when the pilot pulled the stick quickly aft to the stop, the AOA command would ramp in to the preselected AOA limit and remain constant until the pilot released the stick. This technique resulted in nearly identical control system commands for each maneuver.

Flight test data were analyzed for several different configurations, including the unmodified forebody and various combinations of symmetrical longitudinal nose strakes and boundary-layer transition strips. Drawings of the strake and transition strip locations are shown in Fig. 11. Since the wind tunnel model had a larger nose radius (blunter nose) than the full-scale aircraft had initially, it was decided to round off the nose of the aircraft to match the model at the same time 
the strake modification was completed. As a result, the strake-installed configurations also include a modification of the nose tip. The nose tip radii for ship 1 was $.75 \mathrm{in}$. and for ship 2 was .50 in. This results in a ratio of the nose tip radius to the forebody base radius of $r_{n} / r_{b}=.039$ and .026 for ship 1 and ship 2, respectively. The original configuration had a nose bluntness ratio of .003 .

Part of the reason that multiple configuration changes were made simultaneously was that the priority on the flight testing was always on clearing the elevated-g envelope for tactical utility testing. Thus, a thorough investigation of the performance of each configuration change was often not completed. As an example, the strake tests were all completed with a blunted nose tip, while the unstraked tests all had the sharp nose tip.

\section{Results}

The asymmetry analysis technique confirmed that medium to large yawing moment asymmetries existed on both X-31 aircraft at high angles of attack. The results also verified that the asymmetry characteristic was not the same for both aircraft.

\section{Aircraft \#1 (tail number 584)}

\section{Steady-State Maneuvers}

The yawing moment asymmetry for ship 1 during slow (essentially $1-g$ ) decelerations to high AOA conditions is shown in Fig. 12 for several of the flight configurations. The largest asymmetry started to build up beginning at $48^{\circ} \mathrm{AOA}$ to a peak of $\mathrm{Cn}_{0}=-.063$ at approximately $57^{\circ} \mathrm{AOA}$. The asymmetry diminished significantly in magnitude by $66^{\circ} \mathrm{AOA}$.

In response to these asymmetries a transition grit strip was installed on both sides of the forebody and along the sides of the noseboom as shown in Fig. 11. Unfortunately, the data as plotted in Fig. 12 indicate that the asymmetry problem was magnified. Although the largest asymmetry began to build at the same $\mathrm{AOA}\left(48^{\circ}\right)$, the peak asymmetry increased to $\mathrm{Cn}_{0}=-.078$. The $\mathrm{AOA}$ at which the largest asymmetry occurred also appeared to be effected by the transition strip application. The addition of the transition strips increased the AOA at which the largest asymmetry occurred from 58 to $61^{\circ}$.

The replacement of the forebody transition strip with the S1 strake, along with the blunting of the nose tip, effectively delayed the initiation of the yawing moment asymmetry up to an AOA of $55^{\circ}$. A peak asymmetry of $\mathrm{Cn}_{0}=-.040$ occurred at $60^{\circ} \mathrm{AOA}$, after which the asymmetry diminished. As with the unmodified forebody, the aircraft became nearly symmetric by $65^{\circ} \mathrm{AOA}$.

The addition of a boundary-layer transition strip along the forebody aft of the strake resulted in an increase in the asymmetry level. A sharp change in the asymmetry occurred near $55^{\circ} \mathrm{AOA}$. An asymmetry level of $\mathrm{Cn}_{0}<-.050$ remained over an AOA range of 59 to $66^{\circ} \mathrm{AOA}$. Thus, the addition of the forebody transition strip increased the yawing moment asymmetry and caused it to remain at its largest level for a broader AOA range.

Figure 13 tracks the changes in the maximum yawing moment on ship 1 during the configuration modifications. The most important aspect of the asymmetry fingerprint was the maximum value. Figure 13 shows that the yawing moment asymmetry of the basic aircraft was increased with the addition of forebody and noseboom transition strips. The S1 strake and blunted nose, however, provided a reduction of the maximum asymmetry value. Since the forebody tip was rounded at 
the same time that the strakes were added, their individual effects were not distinguishable. The reintroduction of a transition strip aft of the strake again resulted in a detrimental effect on the maximum asymmetry value. Since the noseboom transition strip was not tested independently of other components on ship 1, no clear statement of its effect on the maximum asymmetry value can be made.

Another important aspect of the asymmetry was the AOA range over which the asymmetry affected the aircraft. Figure 14 illustrates the AOA range from the initiation of the yawing moment asymmetry to the AOA at which the asymmetry was negligible. Several important observations can be made from this range plot. First, the strake and blunt nose tip modification delayed the onset of the yawing asymmetry approximately 5 to $55^{\circ} \mathrm{AOA}$. Second, the S1 strake produced a smaller AOA range over which the asymmetries effected the aircraft. Third, all of the configurations tended to become symmetric again near $68^{\circ} \mathrm{AOA}$.

Unfortunately, no configuration was found that eliminated the asymmetry completely. The combination of the S1 strake, blunted nose tip, and noseboom transition strip, however, resulted in the smallest magnitude asymmetry. In addition, this combination had the smallest asymmetric AOA range for ship 1.

\section{Symmetrical Dynamic Maneuvers}

Since the asymmetry problem was first discovered on ship 2 , the strake modifications to ship 1 were made before it flew most of the dynamic maneuvers. As a result, little dynamic data exist for the unstraked forebody configuration. The majority of the flight data were obtained with the S1 strake, blunted nose tip, and noseboom transition strip configuration. A portion of this data also had the forebody transition strips installed as well.

The dynamic asymmetry plots for ship 1 are presented in Figs. 15 and 16. The data obtained from the steady-state decelerations are plotted along with the dynamic data for comparison. In general the asymmetry level during the dynamic maneuvers was less than or equal to the value seen in the 1-g maneuvers. This reduction in asymmetry level during the dynamic portion of the maneuver, however, was not entirely useful. As the aircraft reached its target AOA and the load factor decayed to unity, the asymmetry quickly built up to the steady-state value at that AOA. Thus, the maximum asymmetry defined by the steady-state decelerations provided the worst case levels that had to be accounted for by the control system.

No distinguishable trends in the asymmetry characteristic were noted for varying flight conditions. This may be due to the fact that the aircraft was not flown over a large Reynolds number range $\left(1.5 \times 10^{6}\right.$ to $4.0 \times 10^{6}$ based on a forebody diameter of about $\left.3.2 \mathrm{ft}\right)$.

\section{Aircraft \#2 (tail number 585)}

\section{Steady-State Maneuvers}

The yawing moment asymmetry characteristic of ship 2 was significantly more troublesome than that of aircraft 1. As a result, greater effort was made to reduce the asymmetry on aircraft 2 through configuration changes. In addition to the configurations changes flown with aircraft 1 , an extended length strake, S2, was also tested. 
The asymmetry plot for the unmodified forebody did not show easily distinguishable trends in the asymmetry with AOA. Each maneuver appeared to have a random asymmetry pattern. Plots of the asymmetry vs. AOA show that the maximum yawing moment asymmetry appears to be bounded at $\left|\mathrm{Cn}_{0}\right|<.080$.

The addition of forebody and noseboom transition strips to the X-31 resulted in a more regular asymmetry characteristic than the unmodified forebody during 1-g decelerations, however, larger than usual scatter existed about the average asymmetry. The range of the scatter is plotted in Fig. 17 for this configuration. As was seen with ship 1, the addition of forebody and noseboom transition strips increased the maximum asymmetry level, in this case to almost $\left|C n_{0}\right| \cong .100$. To make matters worse, the asymmetry initially goes to the right to a peak of up to $\mathrm{Cn}_{0}=.050$ at an AOA between 48 and $54^{\circ}$. As the AOA increased, the asymmetry switched to the left, eventually reaching its maximum asymmetry near $67^{\circ} \mathrm{AOA}$. The switching of the asymmetry from the right to left resulted in a change in the yawing moment of about $\Delta \mathrm{Cn} \simeq .10$.

The next configuration change flight tested was the removal of the noseboom transition strip, leaving only the forebody transition strip. Figure 17 shows that two different asymmetry characteristics developed. The first was somewhat traditional, having an onset at $46^{\circ} \mathrm{AOA}$, a peak asymmetry of $\mathrm{Cn}_{0}=-.070$ at $59^{\circ} \mathrm{AOA}$, and a small asymmetry again at $70^{\circ} \mathrm{AOA}$. Other decelerations with forebody grit had significantly worse characteristics. The initial asymmetry started at $38^{\circ} \mathrm{AOA}$, increasing to a level of $\mathrm{Cn}_{0}=-.077$ at $52^{\circ} \mathrm{AOA}$. The asymmetry then rapidly changed signs, increasing to a value of $\mathrm{Cn}_{0}=.088$ by $55^{\circ} \mathrm{AOA}$. Thus, the total yawing moment change over $3^{\circ}$ AOA was $\Delta \mathrm{Cn}=.165$. Since this was the only case in which two different asymmetric characteristics were found on the same configuration, a closer look at the possible causes was made.

The initial purpose of the noseboom transition strip was to ensure that the boundary layer on the flight test noseboom was turbulent prior to separation. It is well known that a turbulent separation off a circular cylinder produces a reduced wake. ${ }^{21}$ Thus, without the transition strip the separation state was subject to the local Reynolds number and noseboom roughness. Calculating the approximate Reynolds number based on noseboom diameter for each of the maneuvers used to create Fig. 17 showed that each of the two asymmetry characteristics occurred over different Reynolds number ranges. Plotting both Reynolds number bands on a chart of the boundary-layer separation state of a circular cylinder as a function of Reynolds number (Fig. 18) shows that a difference in the boundary-layer state at separation probably existed between the two sets of data. The lower Reynolds number data, which likely resulted in a large separation wake, had a sharp change in the asymmetry above $50^{\circ}$ AOA that built up to a large right asymmetry. On the other hand, the higher Reynolds number flow, which produces a turbulent separation, resulted in a smaller wake entering the forebody flowfield. A milder build up in asymmetry was calculated for this group of maneuvers. The higher Reynolds number data more closely matched the data with the noseboom transition strips installed, suggesting that the strip was successful in reducing the noseboom wake, as it was originally intended to do. Thus, the noseboom position and size were not well suited for high AOA flight on the X-31, as the resulting wake interfered with forebody flowfield.

The first real improvement in the yawing moment asymmetries was found with the addition of forebody strakes and the blunting of the nose tip on ship 2 . An error in the nose tip modification on ship 2 was discovered late in the flight testing. The modified nose tip radius was found to be 
about 1.0-in. diameter instead of the 1.5 in. that was specified and completed on ship 1. The data from the S1 and S2 strake flight tests are plotted in Fig. 19. The S1 strake, 1.()-in. diameter blunt nose tip, and noseboom transition strip combination resulted in a comparably slow buildup of asymmetry starting at approximately $50^{\circ}$ AOA. The asymmetry reached a peak value of $\mathrm{Cn}_{0}=-.059$ at an AOA of $60^{\circ}$. As with most other configurations the asymmetry diminished to near zero by $70^{\circ} \mathrm{AOA}$. The addition of a transition strip aft of the $\mathrm{S} 1$ strake increased the maximum asymmetry from $\mathrm{Cn}_{0}=-.059$ to $\mathrm{Cn}_{0}=-.078$. This increase was similar to that seen on aircraft 1 . Since the 20 -in. long S1 strake reduced the maximum yawing moment asymmetry level, a longer 46-in. strake, S2, was installed and flight tested with the blunt nose tip. Unfortunately, little change in the $1-g$ deceleration asymmetries resulted. The longer strake did shift the asymmetry to a higher AOA by approximately $2^{\circ}$.

Figure 20 shows the history of the maximum yawing moment asymmetry through the various configuration modifications. The basic forebody of ship 2 had a larger asymmetry level than that of ship 1. As was found on ship 1, the configuration with the lowest asymmetry was the S1 strake, blunted nose tip, and noseboom transition strip. The S2 strake appeared to perform just as well as the $\mathrm{S} 1$ strake in reducing the maximum asymmetry level. A by-product of the $\mathrm{S} 2$ strake was found to be a nose-up pitching moment penalty at high AOA, requiring approximately $4^{\circ}$ of trailingedge flap to trim out. Since the trailing-edge flaps were used for pitch and roll control it was decided that this penalty was unacceptable and the S2 strakes were removed.

The AOA range over which the yawing moment asymmetries acted on ship 2 is outlined in Fig. 21. The installation of the forebody strakes delayed the initiation of the asymmetry to approximately $50^{\circ} \mathrm{AOA}$ from $38^{\circ} \mathrm{AOA}$. The peak asymmetry occurred between 55 and $65^{\circ} \mathrm{AOA}$ on ship 2. With each configuration, the asymmetry diminished to a negligible level by $70^{\circ} \mathrm{AOA}$, as was the case with ship 1 .

\section{Symmetrical Dynamic Maneuvers}

Ship 2 was the first of the X-31 aircraft to begin the elevated- $g$, post-stall maneuvering. The initial attempt at the envelope clearance used the forebody and noseboom transition grit configuration. Shortly into this clearance a departure from controlled flight occurred while the pilot was performing a $2-g$ split-S maneuver to $60^{\circ} \mathrm{AOA}$. The data analysis showed that the departure was triggered by an unmodeled yawing moment. Using the current technique the asymmetry was calculated and is shown in Fig. 22. The maximum asymmetry during the maneuver was found to be $\mathrm{Cn}_{0}=.125$. As stated, this event triggered the development and installation of forebody strakes on both aircraft. Since the departure occurred so early in the envelope expansion, little data exist of the dynamic effects of the asymmetries without one of the strakes installed.

The yawing moment asymmetries of ship 2 during symmetrical dynamic maneuvers with the strakes and blunted nose tip are presented in Fig. 23 for several Reynolds number ranges. The maximum asymmetry levels were well under those measured for the $1-g$ deceleration maneuvers. The S1 strake had a slight right asymmetry above $46^{\circ} \mathrm{AOA}$, moving to a left asymmetry above $60^{\circ}$ AOA. As noted on ship 1 , the magnitude of the asymmetry increased toward the deceleration values as the aircraft angle-of-attack rate decreased to zero. Unlike ship 1, the magnitude of the yawing asymmetry remained slightly less than the deceleration value near the peaks at $60^{\circ} \mathrm{AOA}$. At lower $\mathrm{AOA}$ (near $50^{\circ}$ ), the dynamic maneuvers produced larger asymmetry levels than those 
seen during the $1-g$ decelerations. In addition, the maximum asymmetry measured when capturing $50^{\circ} \mathrm{AOA}$ increased with increasing aircraft velocity.

\section{Comparison of X-31 Aircraft}

Although no significant manufacturing differences were known between the two unmodified X-31 aircraft, differences between the basic airframe high AOA yawing moment asymmetries were found. Comparing Figs. 13 and 20 shows that the basic aircraft maximum yawing moment on ship 2 was approximately 27 percent higher than ship 1 . When the nose tips were rounded, ship 1 had a diameter of about $1.5 \mathrm{in}$. while ship 2 had a diameter of $1.0 \mathrm{in.}$

Several of the aircraft modifications produced similar increments in the yawing moment magnitude. The addition of forebody and noseboom transition strips resulted in an increase of the maximum yawing moment asymmetry of approximately $\Delta \mathrm{Cn}_{0}=.016$ on both aircraft. The transition strip ensured that a turbulent boundary layer existed over the full length of the forebody. As shown in Fig. 8, a fully turbulent boundary-layer separation typically results in the maximum asymmetry levels. If some locally transitional flow conditions existed on the X-31 forebody initially, the boundary-layer transition strip may have eliminated the transitional flow's beneficial effect. The addition of the S1 strake, blunted nose tip, and noseboom transition strips also had a similar effect on both aircraft. The maximum measured asymmetry was reduced by approximately $\Delta \mathrm{Cn}_{0}=.022$ on each aircraft.

In addition to the maximum asymmetry differences, the two aircraft had different AOA ranges over which the asymmetry acted. A comparison of Figs. 14 and 21 shows several variations between the aircraft. The initiation of the asymmetry with the forebody and noseboom transition strips present occurred approximately $10^{\circ}$ AOA earlier on ship 2 . With the S1 strake and blunted nose tip in place the asymmetry initiated approximately $5^{\circ}$ AOA earlier on ship 2 . The yawing moment asymmetry tended to fade at a slightly lower AOA on ship 1 . As a result, ship 2 had a larger AOA range subjected to yawing moment asymmetries.

\section{Comparison to Wind Tunnel}

The wind tunnel data ${ }^{2}$ did not predict the asymmetry magnitudes that were found in flight test. A difference in the model nose tip diameter between the model and flight test vehicle was found for the unmodified forebody configuration. The model had a full-scale nose tip diameter of 1.20 in., while the aircraft nose tip diameter was closer to $.125 \mathrm{in}$. before the tip was modified. When the strakes were installed on the X-31, the nose tip was rounded to match the wind tunnel model diameter. Figure 24 shows a plot of the yawing moment asymmetry measured on a 19-percent scale model along with the values calculated from flight test data for the clean and straked forebody configurations. Clearly, the wind tunnel test did not predict the magnitude of the asymmetry that was measured in flight. The wind tunnel test did show that the installation of strakes was effective in reducing the high AOA yawing moment asymmetry.

\section{Effects on Maneuvering}

The high AOA yawing moment asymmetries of the X-31 aircraft significantly impacted the flight envelope clearance, which delayed the beginning of the tactical utility testing by several months. Although the aircraft responses were not objectionable to the test pilots, control surface saturations occurred in the roll and yaw axes as a result of the asymmetries. 
The yawing moment asymmetries contributed to the saturation of the thrust vector vanes during the initiation of some of the stability axis rolling maneuvers. The short duration thrust vector vane saturation occurred more often at the beginning of rolls to the left at $50^{\circ} \mathrm{AOA}$ and to the right at $60^{\circ} \mathrm{AOA}$. This corresponds to rolls in the opposite direction of the asymmetry. This is not unexpected since the thrust vector system must provide a yawing moment to counter the asymmetry in addition to coordinating the rolling motion. These saturations occurred even when the available thrust vector paddle deflection was increased from 26 to $35^{\circ}$ to provide additional control power. Unlike traditional control surfaces, which increase in power with dynamic pressure, the available yawing control power from the thrust vectoring system is a constant for a given thrust setting. Figure 25 is a plot of the maximum yawing moment coefficient provided by the thrust vectoring system as a function of the calibrated airspeed. It is apparent from the graph that the amount of asymmetry that can be controlled by the thrust vector system declines rapidly with increasing airspeed.

Control saturations were also encountered in the roll axis for differential deflection of the trailingedge flaps. The problem was only critical for the left rolling maneuvers, which required a significant average trailing-edge down deflection of the flaps to counter the engine gyroscopic coupling. As either flap moved down, its effectiveness decreased, requiring additional deflection to get the same moment. The combination of the symmetrical flap deflection due to gyroscopic coupling and the increased differential required to coordinate the rolling motion often drove the left trailing-edge flap near or to the position limit. A time history of a typical case is shown in Fig. 26.

A possible solution to the trailing-edge flap saturation problem would use the thrust vectoring system in pitch to compensate for the engine gyroscopic coupling. This would allow the full power of the trailing-edge flaps to be used only for roll control. Since the thrust vector system is only fully used during the initiation of the roll, it is available to provide gyroscopic compensation after the roll is established.

\section{Conclusions}

An analysis of the static and dynamic yawing moment asymmetry of the X-31 aircraft from flight data was completed for the basic and several modified forebody configurations. The important findings and observations are summarized in the following.

- The combination of forebody strakes and blunt nose tip:

- increased the AOA at which the asymmetry initiated by 7 to $12^{\circ}$

- reduced the maximum asymmetry

- eliminated the random variations of the asymmetry and made the asymmetry repeatable

- The installation of boundary-layer transition strips along the forebody:

- increased the level of the yawing moment asymmetry

- in some cases, widened the AOA range over which the asymmetries acted 
- reduced the random asymmetry behavior of the unmodified forebody on ship 2

- The installation of boundary-layer transition strips along the noseboom:

- ensured that a turbulent separation existed on the noseboom, thereby minimizing the noseboom wake

- The two X-31 aircraft had different yawing moment asymmetry characteristics. Ship 2 had consistently larger yawing moment asymmetries than ship 1 . In addition, the yawing moment asymmetries initiated at a lower AOA on ship 2.

\section{Recommendations}

- Forebody-mounted nosebooms should be avoided whenever possible on high AOA aircraft as their wake can influence the forebody vortex development.

- Caution should be used when using transition strips at high AOA, as larger asymmetries can be created.

- The possibility of asymmetries should be included in the design of control surfaces for high AOA aircraft to ensure that enough power is available to coordinate maneuvering.

- Wind tunnel tests should not be relied upon to predict the yawing moment asymmetry magnitude.

- The gyroscopic coupling task on the X-31 should be reallocated from the trailing-edge flaps to the thrust vectoring vanes. This change would eliminate the trailing-edge flap saturations and open up the possibility of increasing the elevated-g envelope at high AOA.

\section{Acknowledgments}

A special thanks is owed to Dave Fisher and John Del Frate of NASA Dryden Flight Research Center for their many discussions and recommendations on forebody aerodynamics. The plot of the thrust vector control power is courtesy of Jose Villeta of Rockwell International.

\section{References}

${ }^{1}$ Fisher, David F. and Brent R. Cobleigh, "Controlling Forebody Asymmetries In-FlightExperience with Boundary Layer Transition Strips," AIAA 94-1826, Applied Aerodynamics Conference, Colorado Springs, CO, June 20, 1994.

${ }^{2}$ Croom, Mark A., David J. Fratello, Raymond D. Whipple, Matthew J. O'Rourke, and Todd W. Trilling, "Dynamic Model Testing of the X-31 Configuration for High Angle of Attack Flight Dynamics Research," AIAA 93-3674 CP, Flight Mechanics Conference, Monterey, CA, Aug. 9-11, 1993.

${ }^{3}$ Keener, Earl P., Gary T. Chapman, Lee Cohen, and Jamshid Taleghani, Side Forces on a Tangent Ogive Forebody with a Fineness Ratio of 3.5 at High Angles of Attack and Mach Numbers from .1 to .7, NASA TM X-3437, 1977. 
${ }^{4}$ Lamont. P.J.. "Pressure Measurements on an Ogive-Cylinder at High Angles of Atlack with Laminar. Transitional. or Turbulent Separation." AIAA 80-1556, Jan. 1980.

SMoskovitz. (.. R. Hall. and F. DeJarnette. "Experimental Investigation of a New Device to Control the Asymmetric Flowfield on Forebodies at Large Angles of Attack." AlAA $9(0-1)(169$. 28th Aerospace Sciences Meeting. Reno. NV, Jan. 8-11, 1990.

"Bridges, David H. and Hans G. Hornung. "Elliptic Cross Section Tip Effects on the Vortex Wake of an Axisymmetric Body at High Angle of Attack," AIAA 93-2960. 24th Fluid Dynamics Conference, Orlando, FL, July 6-9, 1993.

${ }^{7}$ Chapman G.T., E.R. Keener, and G.N. Malcolm, Asymmetric Aerodynamic Forces on Aircraft Forebodies at High Angle of Attack - Some Design Guides, AGARD CP-199. Nov. 1975.

${ }^{8}$ Kruse, Robert L., Earl R. Keener, Gary T. Chapman, and Gary Claser, Investigation of the Asymmetric Aerodynamic Characteristics of Cylindrical Bodies of Revolution With Variations in Nose Geometry and Rotational Orientation at Angles of Attack to $58^{\circ}$ and Mach Numbers to 2, NASA TM-78533, 1979.

${ }^{9}$ Moskovitz, Cary A., Robert M. Hall, and F.R. DeJarnette, "Effects of Nose Bluntness, Roughness and Surface Perturbations on the Asymmetric Flow Past Slender Bodies at Large Angles of Attack," AlAA 89-2236-CP, 1989.

${ }^{10}$ Lamont, P.J., "The Complex Asymmetric Flow Over a 3.5D Ogive Nose and Cylindrical Afterbody at High Angles of Attack," AIAA 82-0053, 20th Aerospace Sciences Meeting, Orlando, FL, Jan. 11-14, 1982.

${ }^{11}$ Fisher, David F., David M. Richwine, and Stephen Landers, Correlation of Forebody Pressures and Aircraft Yawing Moments on the X-29A Aircraft at High Angles of Attack, NASA TM-4417, 1992.

${ }^{12}$ Skow, A.M. and G.E. Ericsson, "Modern Fighter Aircraft Design for High-Angle-of-Attack Maneuvering," AGARD LS-121 High-Angle-of-Attack Aerodynamics, Mar. 1982, pp. 4-1 to 4-59.

${ }^{13}$ Coe, Paul L., Jr., Joseph R. Chambers, and William Letko, Asymmetrical Lateral-Directional Characteristics of Pointed Bodies of Revolution at High Angles of Attack, NASA TN D-7095, 1972.

${ }^{14}$ Malcolm, Gerald N. and T.T. Ng, "Aerodynamic Control of Aircraft by Forebody Vortex Manipulation," AIAA 90-1827, Aerospace Engineering Conference and Show, Los Angeles, CA, Feb. 13-15, 1990.

${ }^{15}$ Ng, T.T. and G.N. Malcolm, “Aerodynamic Control Using Forebody Strakes,” AIAA 91-0618, 29th Aerospace Sciences Meeting, Reno, NV, Jan. 7-10, 1991.

${ }^{16}$ Hassell, James L., Jr. and Donald E. Hewes, Investigation of the Subsonic Stability and Control Characteristics of a 1/7-Scale Model of the North American X-15 Airplane With and Without Fuselage Forebody Strakes, NASA TM X-210, 1960.

${ }^{17}$ Rao, D.M., "Side-Force Alleviation on Slender, Pointed Forebodies at High Angles of Attack," AlAA 78-1339, Atmospheric Flight Mechanics Conference, Palo Alto, CA, Aug. 7-9, 1978. 
"Modi. V.J. and A.C. Stewart. "Approach to Side Force Alleviation through Modification of the Pointed Forebody Geometry." AlAA 9(1-2837. 1990).

${ }^{14}$ Hunt. B.L.. "Asymmetric Vortex Forees and Wakes on Slender Bodies." AlAA s2-1330. 9th Atmospheric Flight Mechanics Conference. San Diego. CA. Aug. 9-11. 1982.

2"Ericsson. L.E.. "Control of Forebody. Flow Asymmetry - A Critical Review:" AlAA 9012533CP. 1990 .

"Shevell, Richard S.. Fundamentals of Flight. Prentice-Hall Inc., Englewood Cliffs, NJ. 1983.

2Pick, George S.. "Investigation of Side Forces on Ogive-Cylinder Bodies at High Angles of Attack in the $M=0.5$ to 1.1 Range," AlAA 71-570. 4th Fluid and Plasma Dynamics Conference. Palo Alto, CA, June 1971.

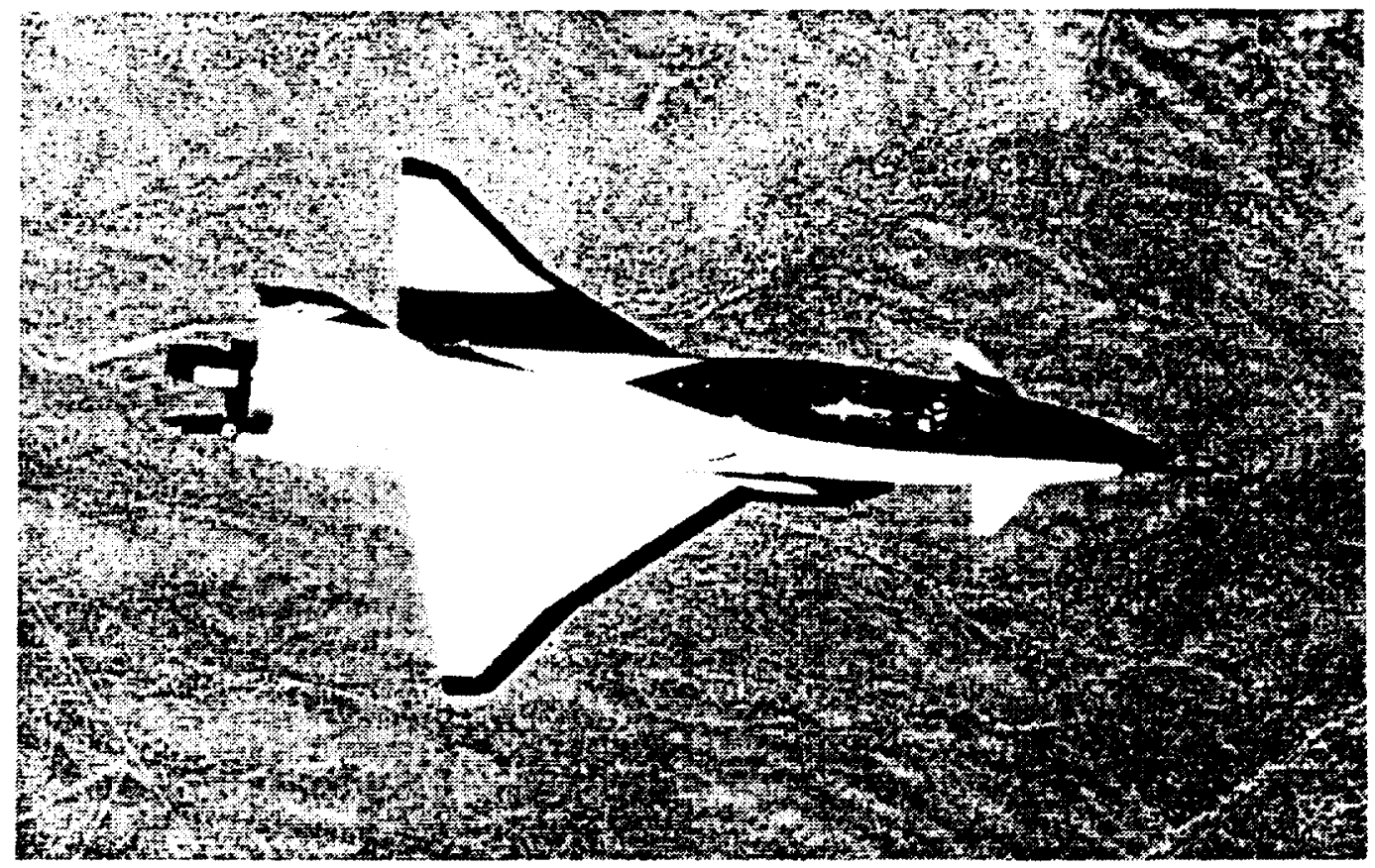

EC $9209164-9$

Fig. 1. Photograph of the X-31 aircraft. 


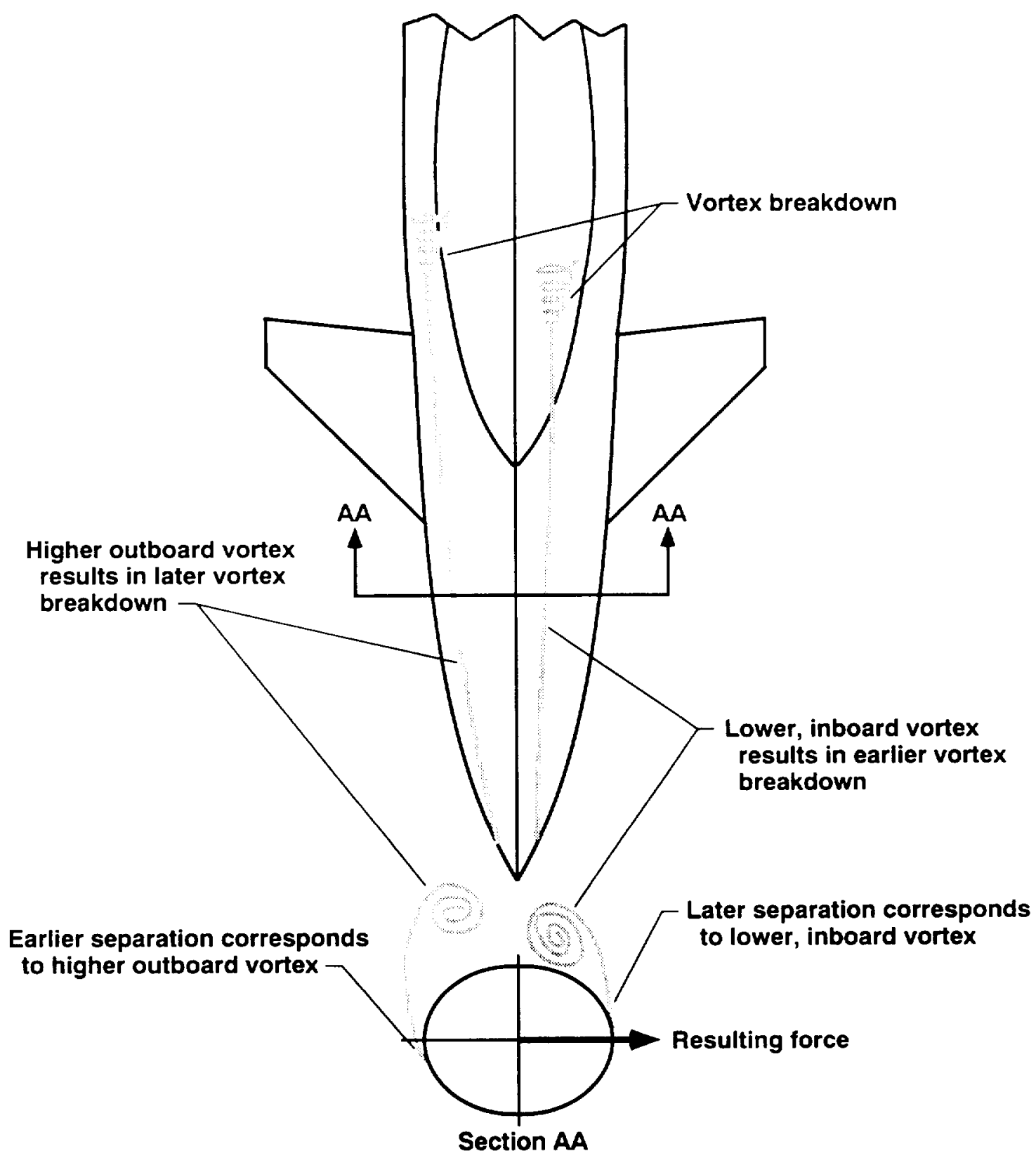

940002

Fig. 2. Sketch of asymmetric forebody vortices on aircraft forebody. 


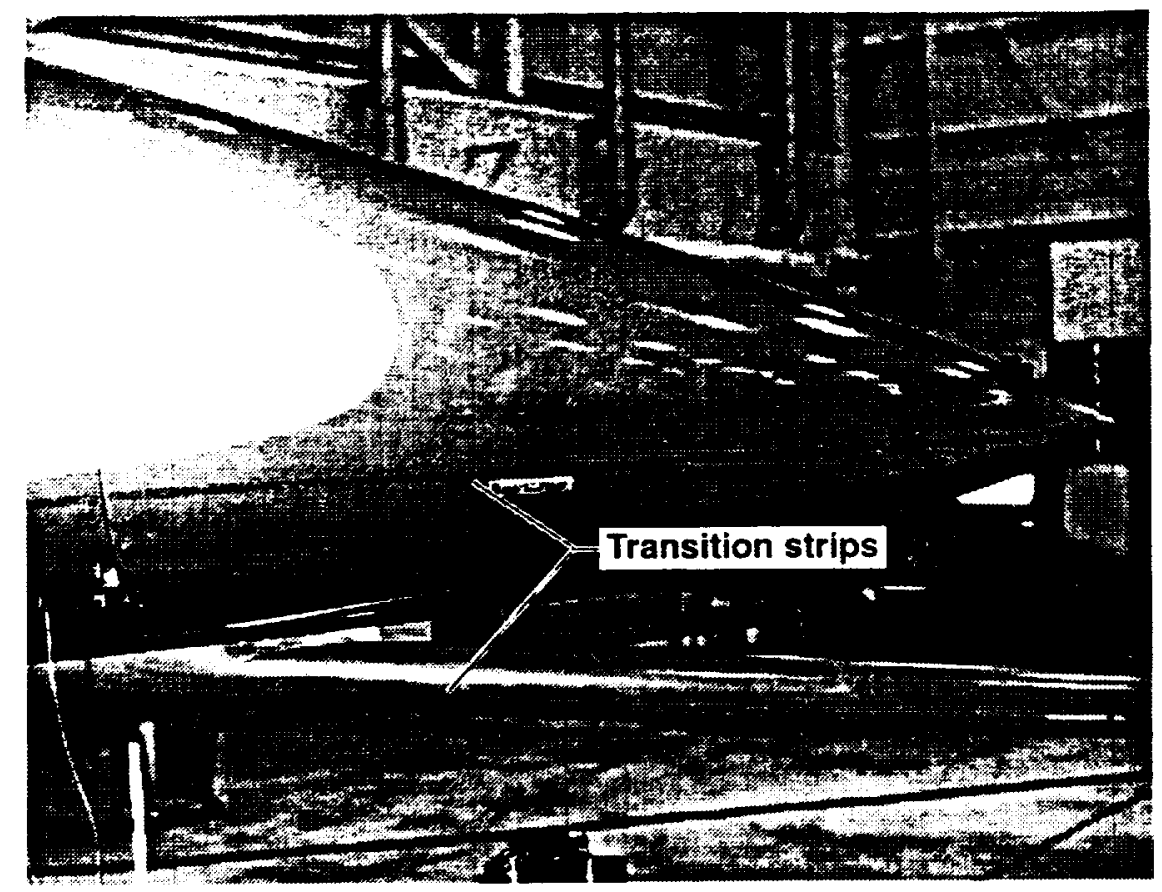

$4+11197$

Fig. 3. Photograph of the forebody and noseboom transition strip. (EC 92 12083-6).

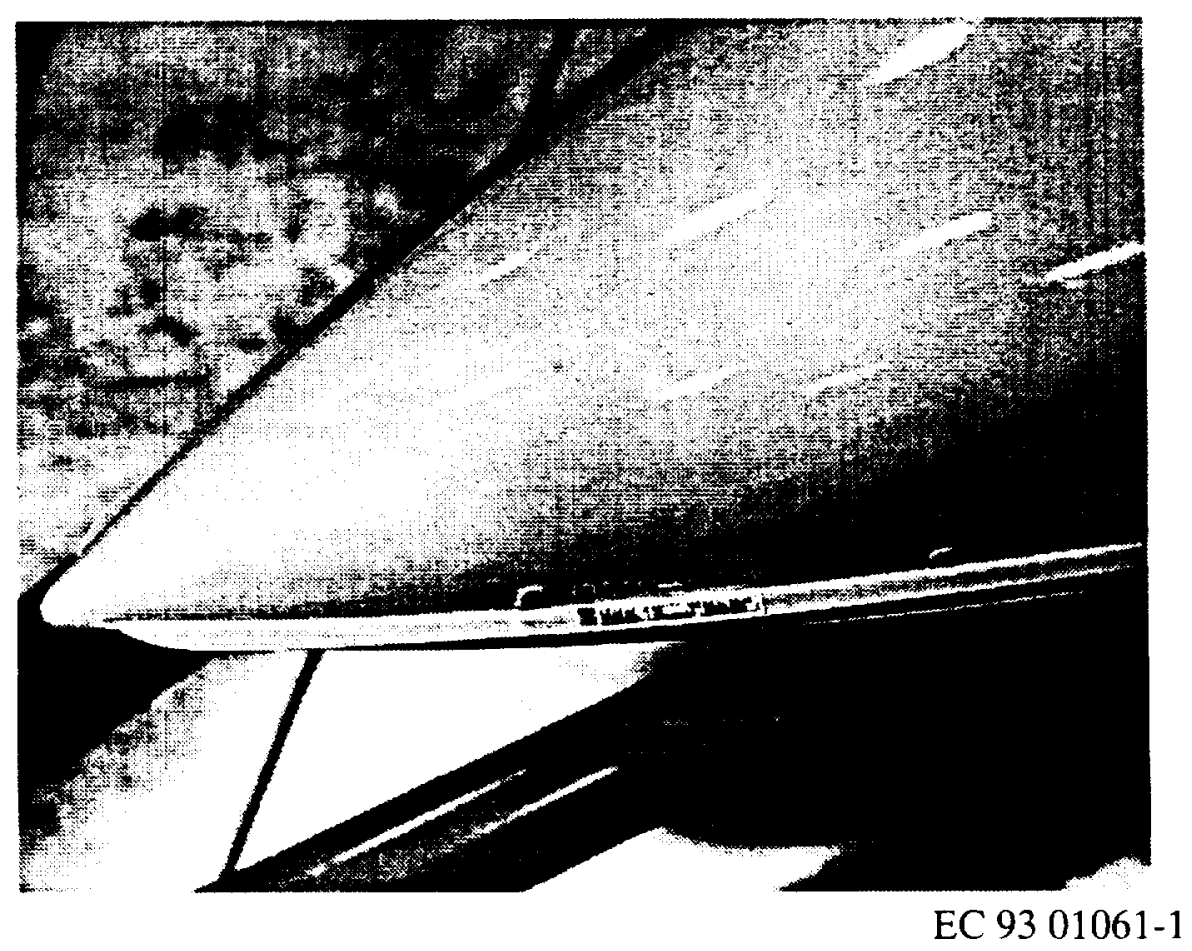

Fig. 4. Photograph of the 20 -in. strakes installed on the $X-31$ forebody. 


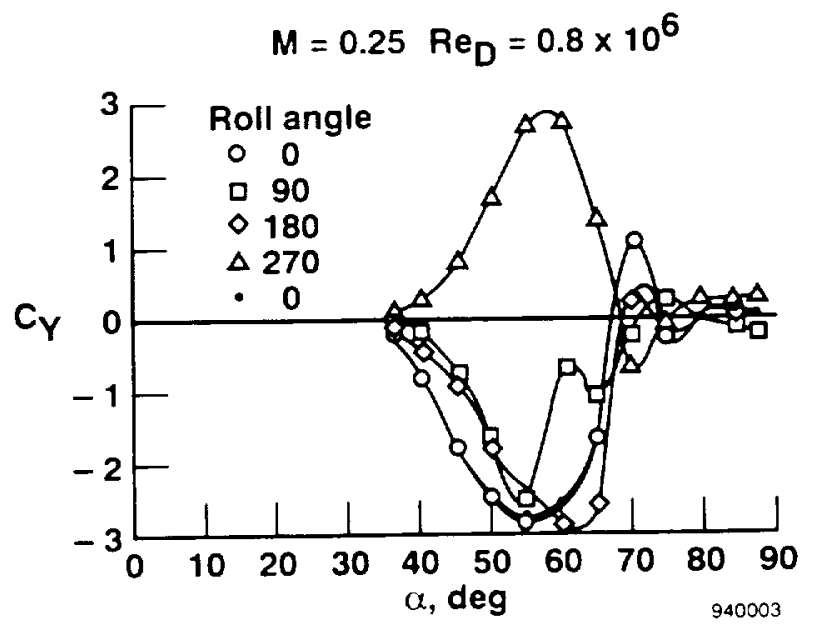

Fig. 5. Side force asymmetry of a $3.0 \mathrm{l} / \mathrm{d}$ ogive with as a function of AOA for several roll angles (from ref. 3).

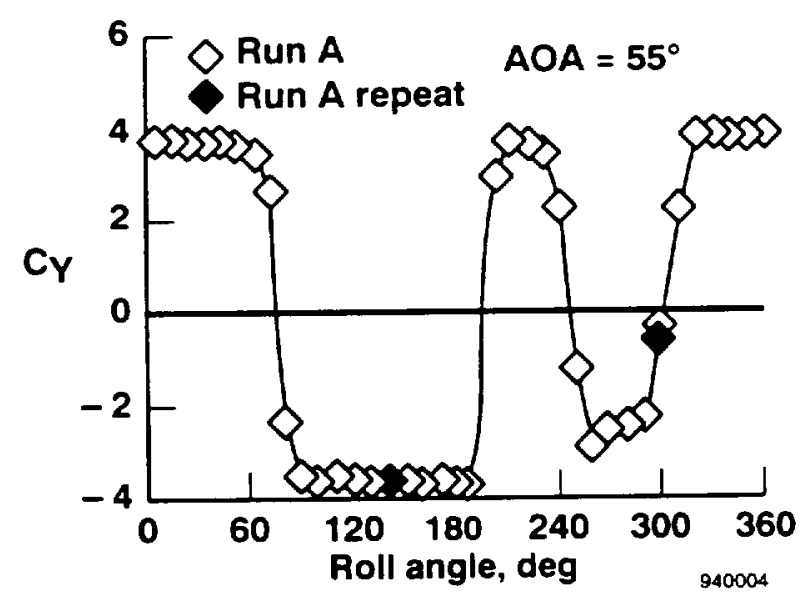

Fig. 6. Variation of side force coefficient on a $3.0 \mathrm{l} / \mathrm{d}$ ogive cylinder with model roll angle (from ref. 4). 


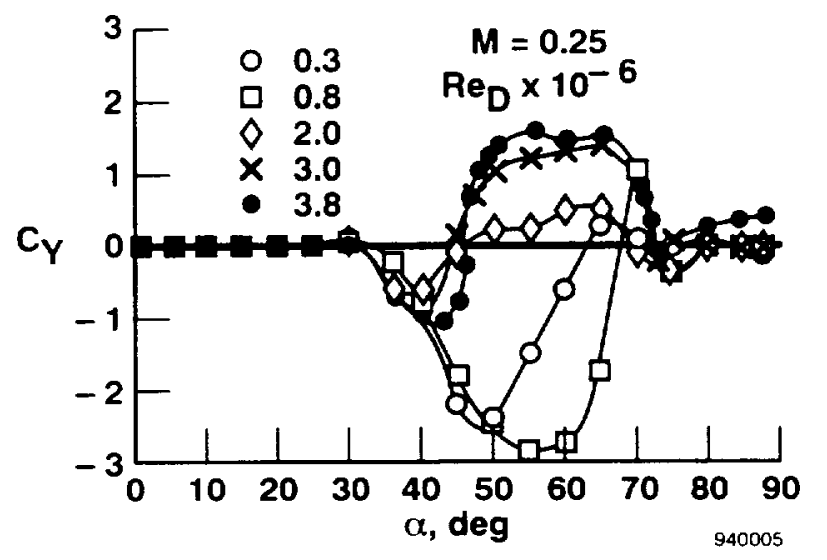

Fig. 7. Effect of Reynolds number on the side force of a 3.5 l/d ogive (from ref. 3).

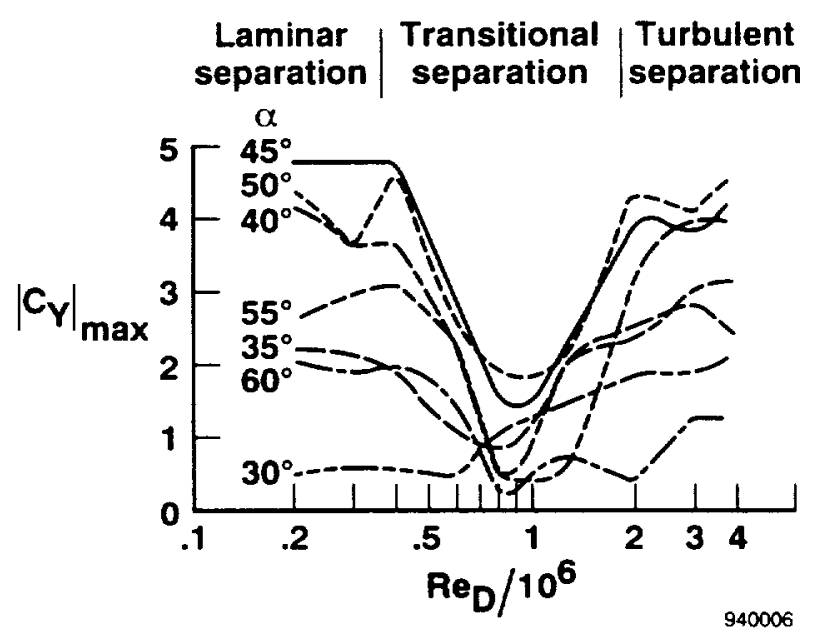

Fig. 8. Variation of maximum side force with Reynolds number for several angles of attack (from ref. 10). 


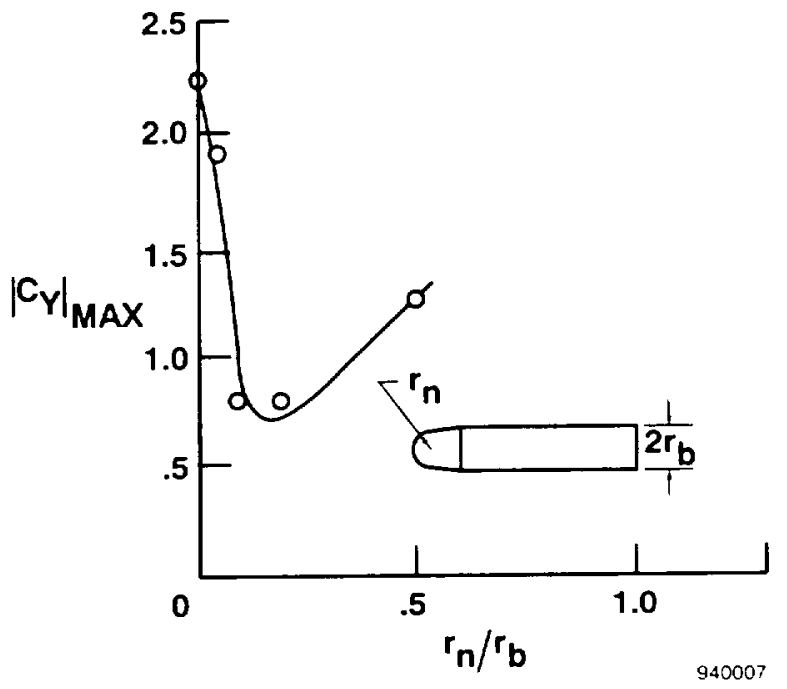

Fig. 9. Effect of nose bluntness on maximum side force asymmetry (from ref. 22).

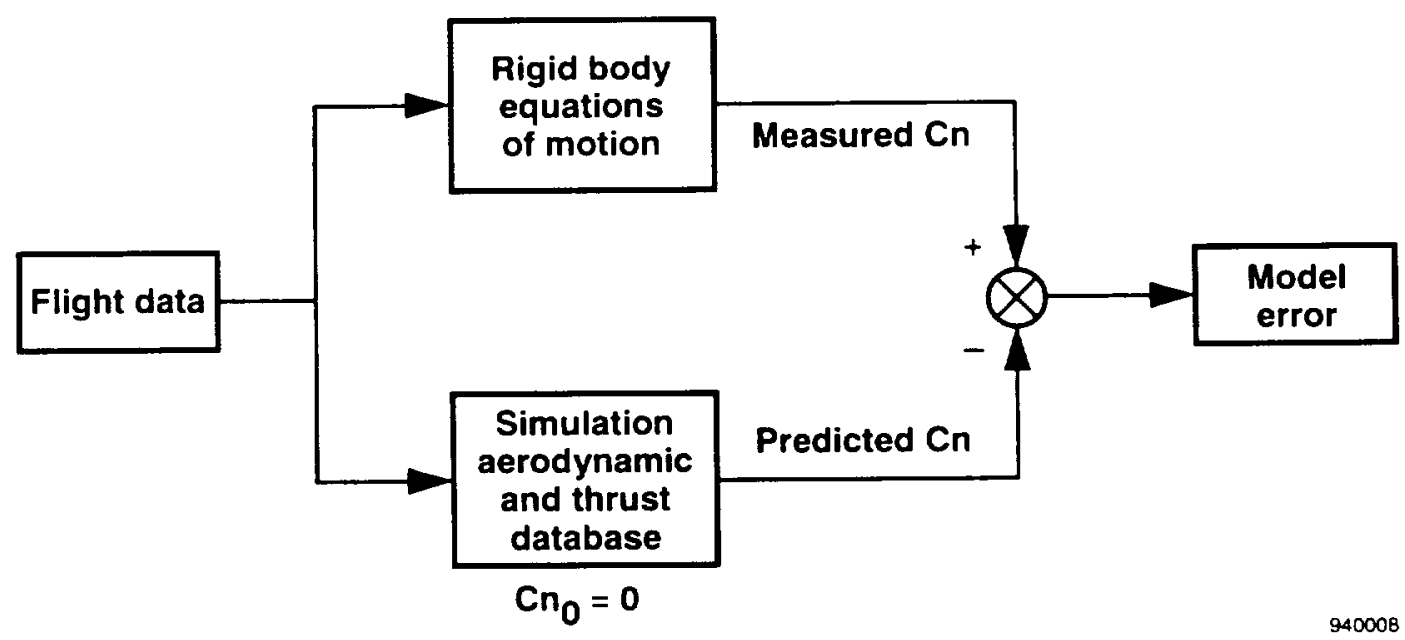

Fig. 10. Asymmetry calculation method. 

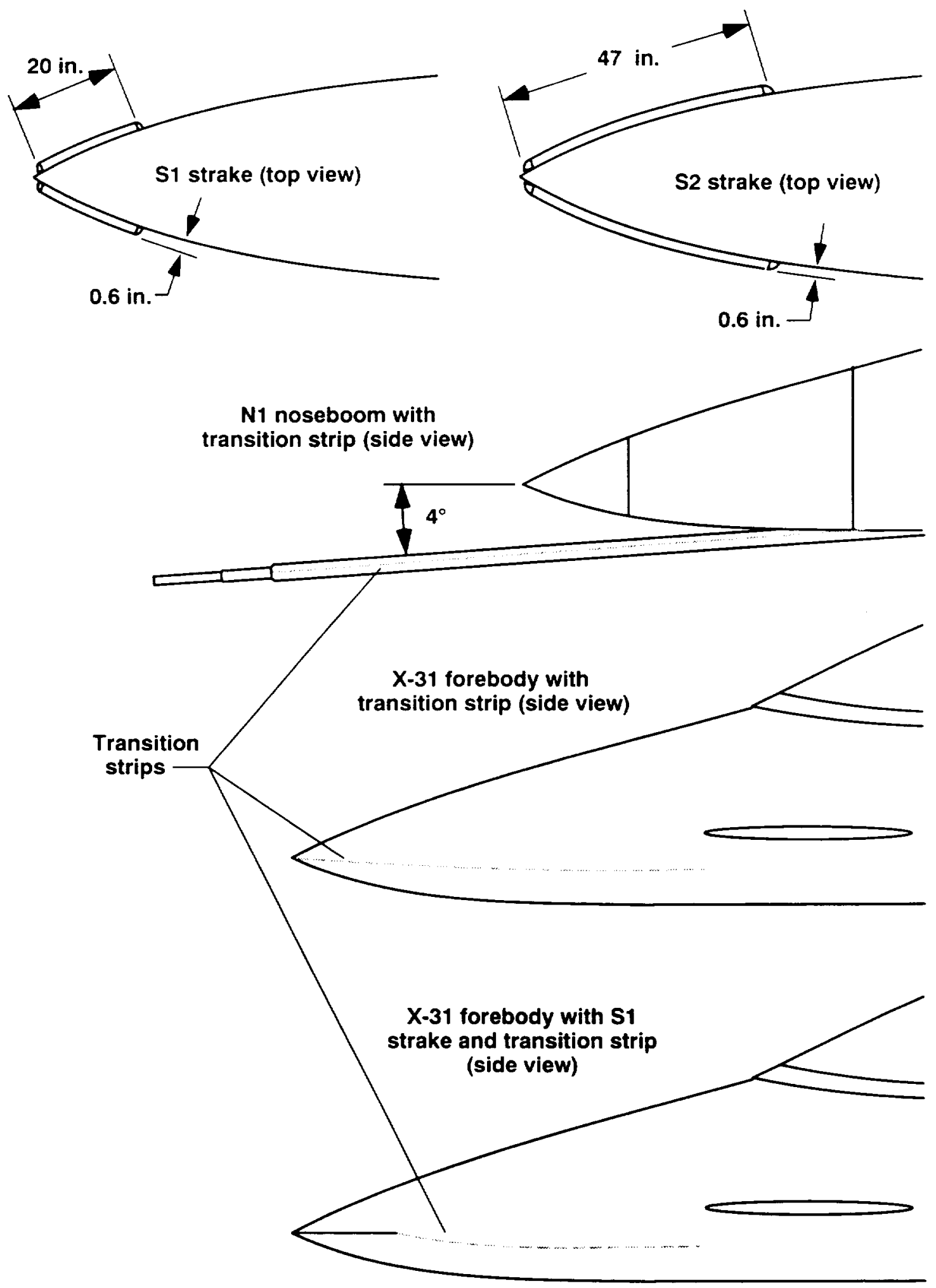

Fig. 11. Boundary-layer transition strips and strakes tested. 


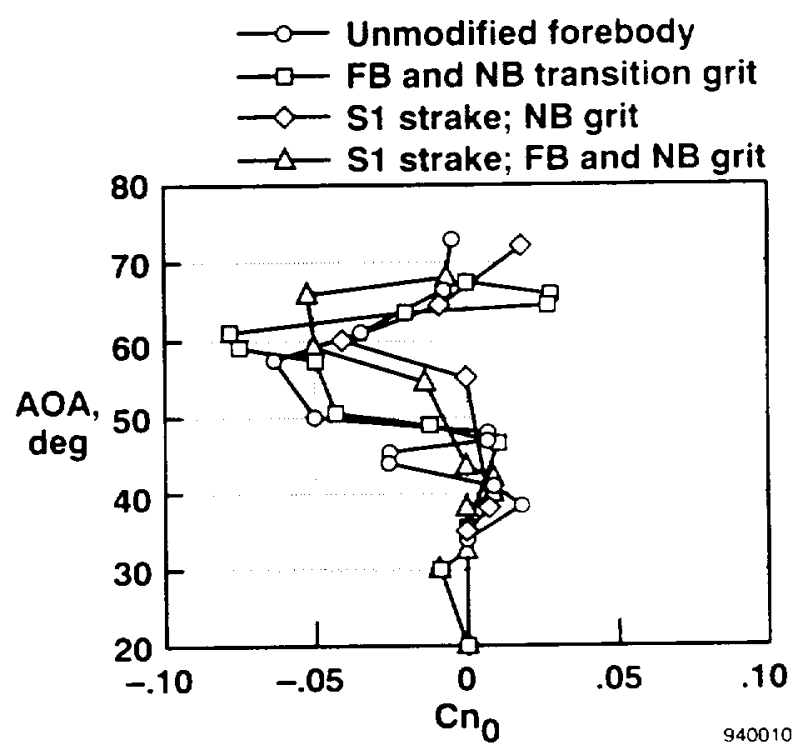

Fig. 12. Variation of yawing moment asymmetry with AOA for ship 1, 1-g maneuvers.

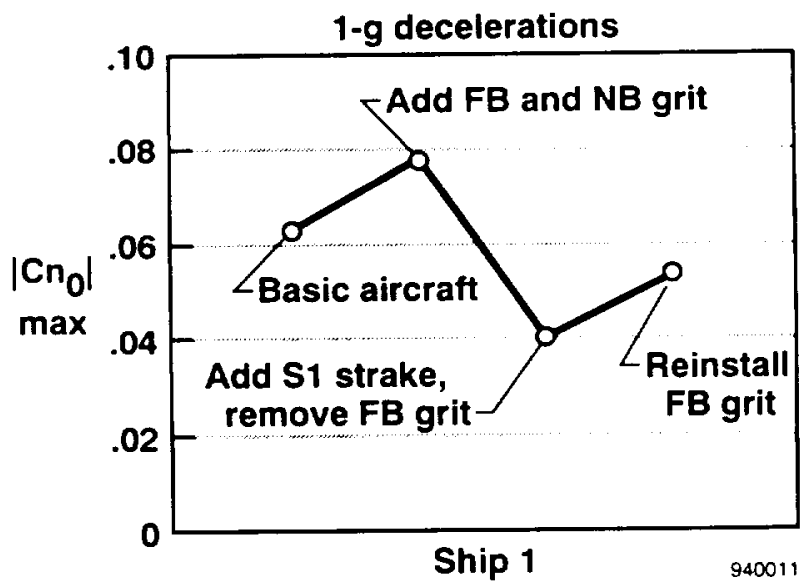

Fig. 13. Maximum yawing moment coefficient with varying ship 1 configuration changes. 


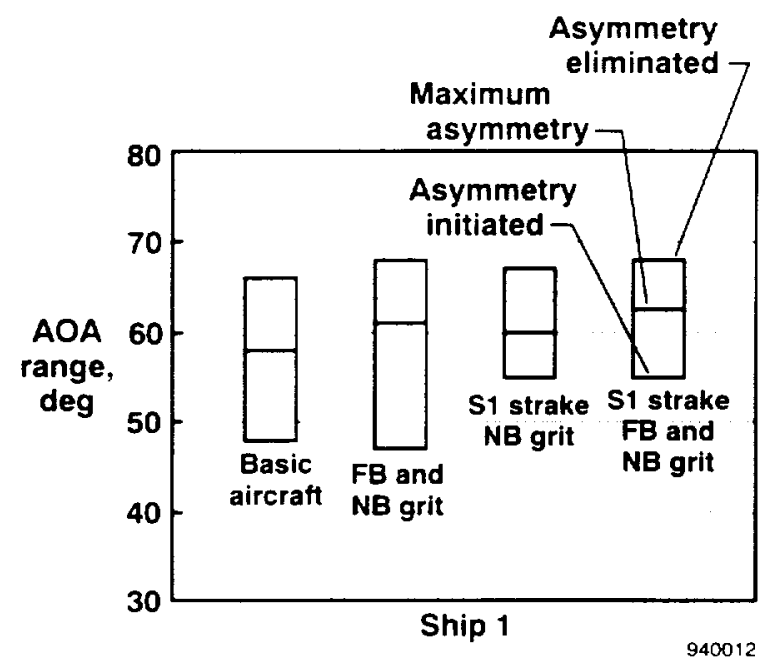

Fig. 14. AOA range of asymmetric yawing moments with varying ship 1 configuration changes.

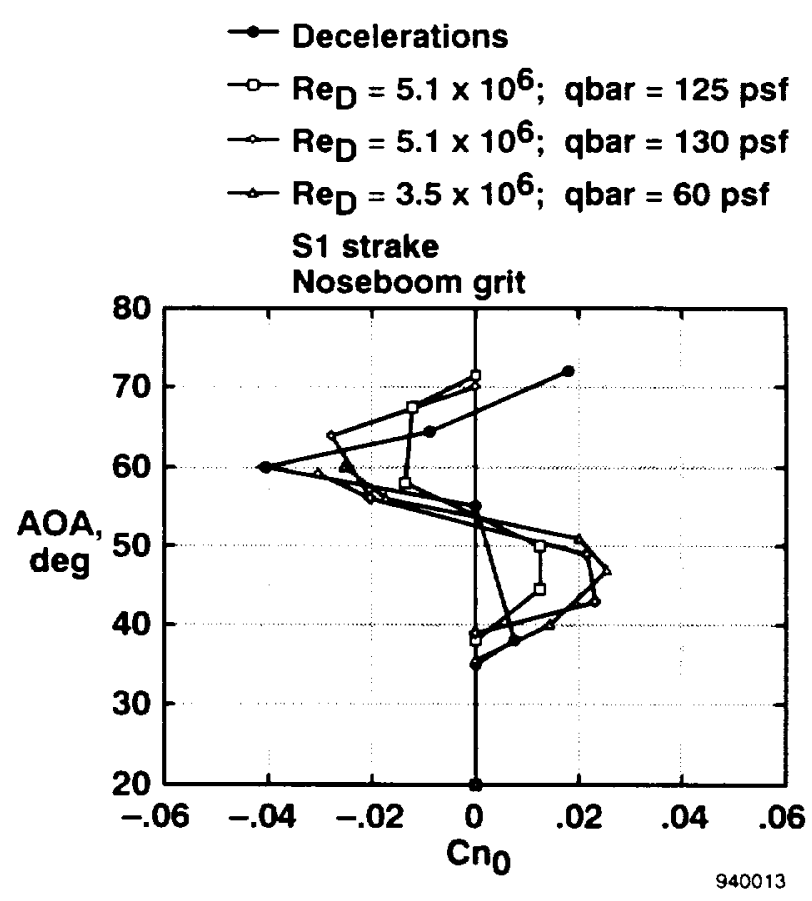

Fig. 15. Variation of yawing moment asymmetry with AOA for ship 1 dynamic maneuvers with the $\mathrm{S} 1$ strakes and noseboom transition strip. 


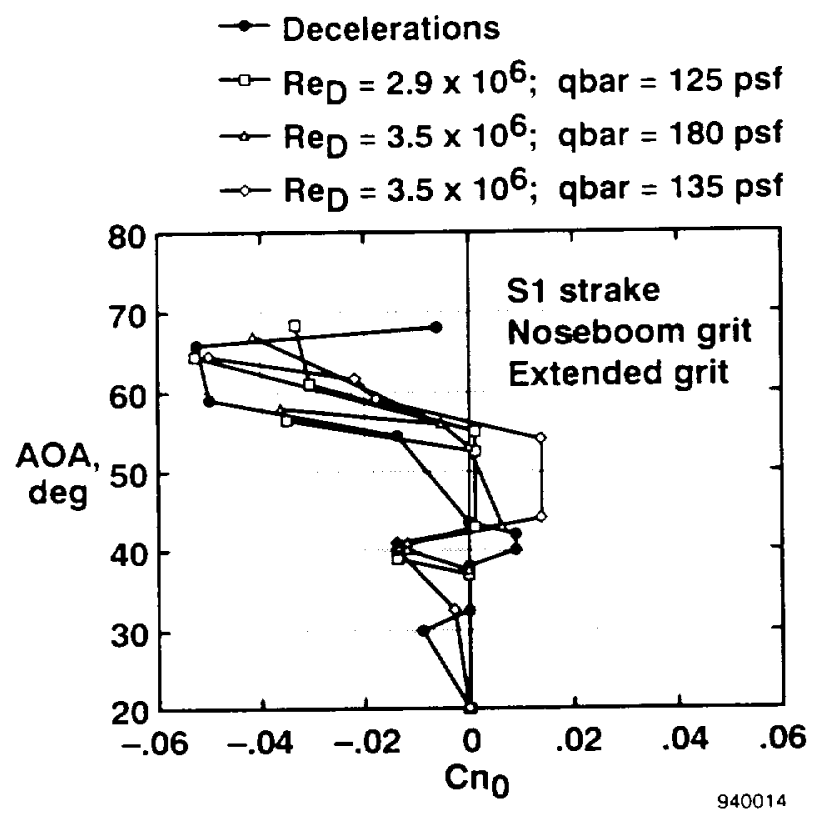

Fig. 16. Variation of yawing moment asymmetry with AOA for ship 1 dynamic maneuvers with the S1 strakes, forebody transition strip, and noseboom transition strip.

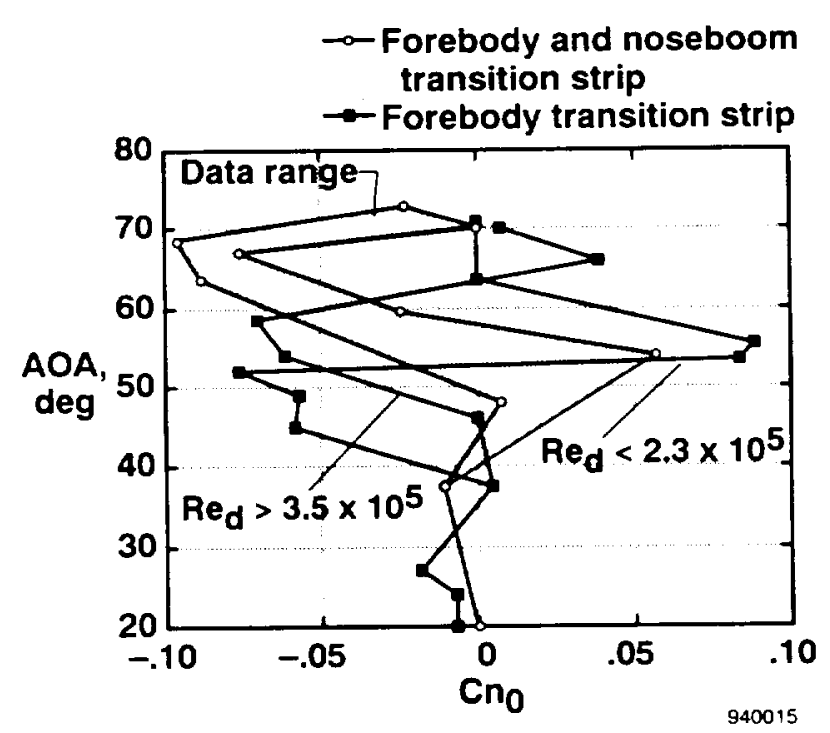

Fig. 17. Variation of yawing moment asymmetry with AOA for ship 2 without strakes, 1-g maneuvers. 


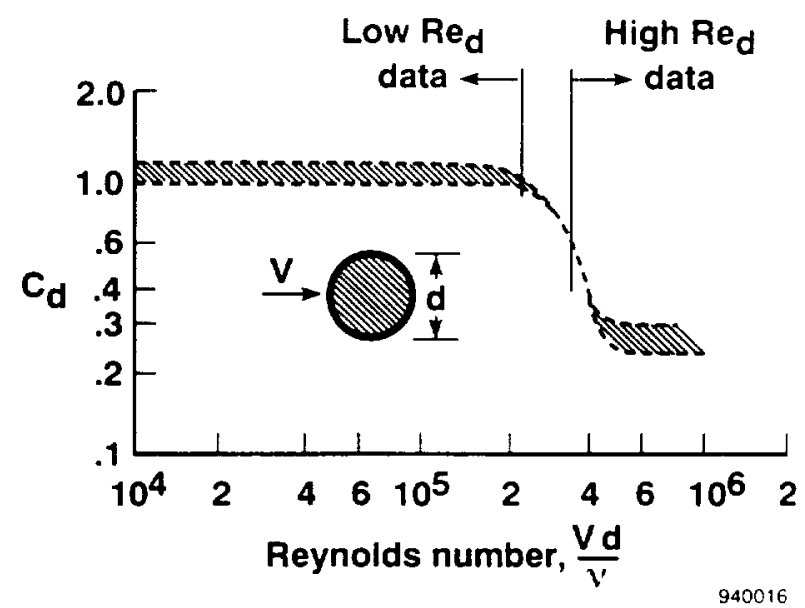

Fig. 18. Variation of drag coefficient with Reynolds number for a circular cylinder (from ref. 21).

$-\infty$ S1 strake; forebody and noseboom transition strip

$\rightarrow$ S1 strake; noseboom transition strip

- S2 strake; noseboom transition strip

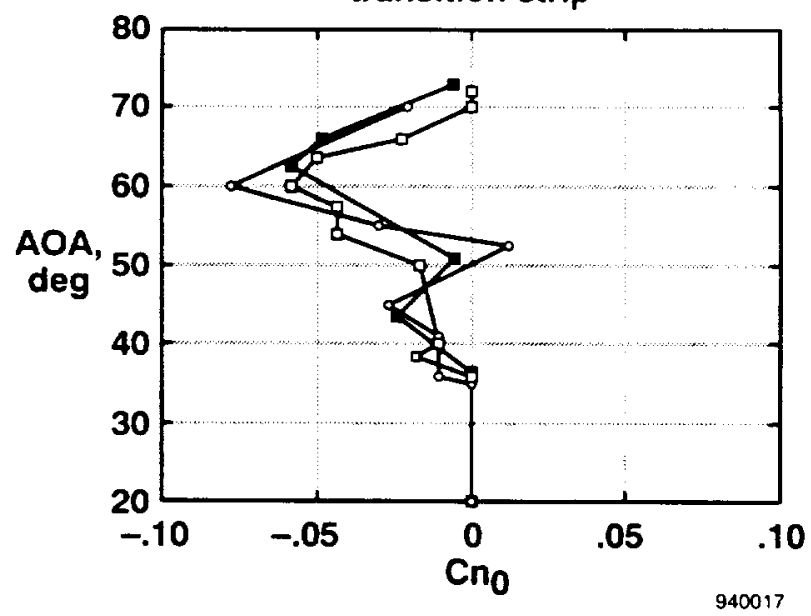

Fig. 19. Variation of yawing moment asymmetry with AOA for ship 2 with strakes, 1-g maneuvers. 


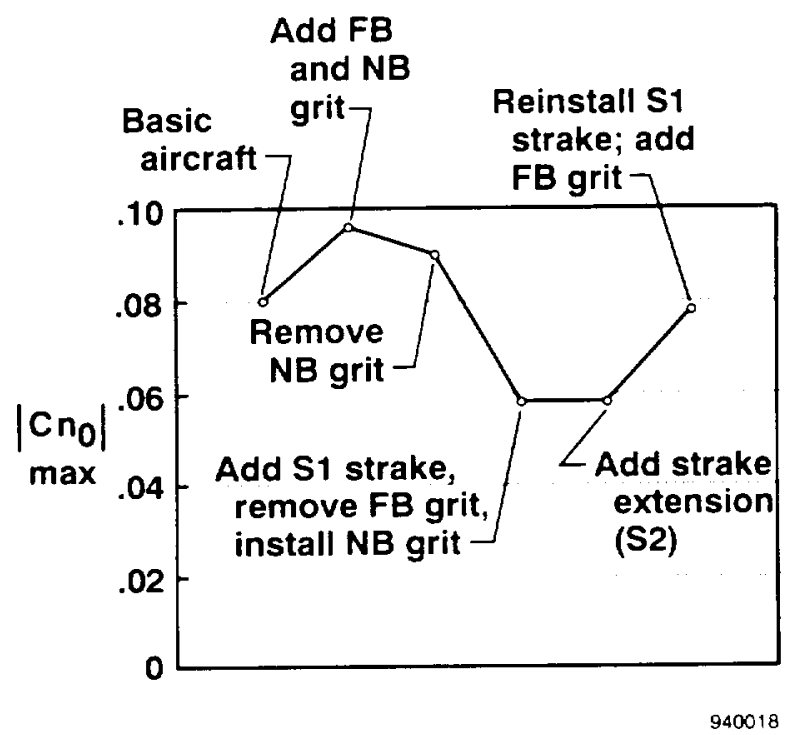

Fig. 20. Maximum yawing moment coefficient with varying ship 2 configuration changes.

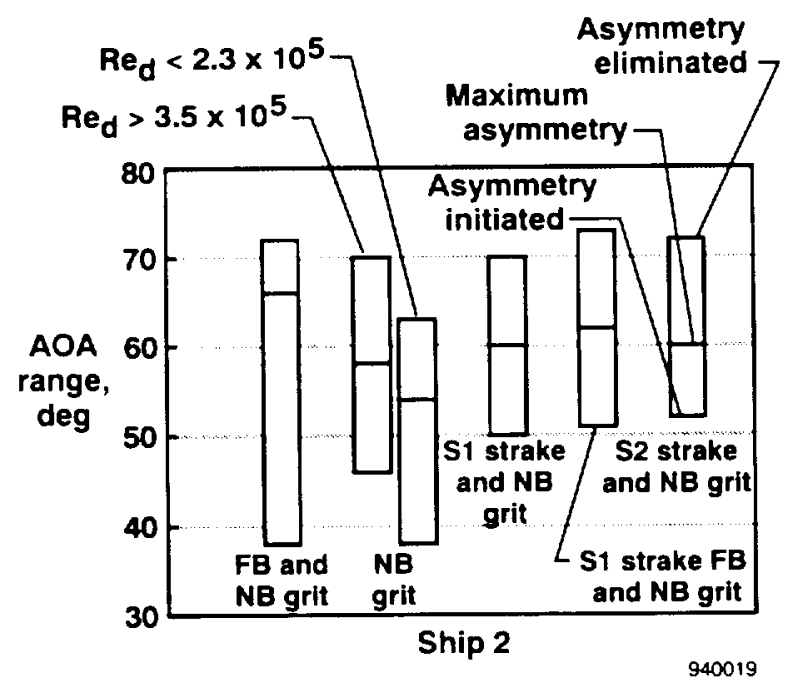

Fig. 21. AOA range of asymmetric yawing moments with varying ship 2 configuration changes. 


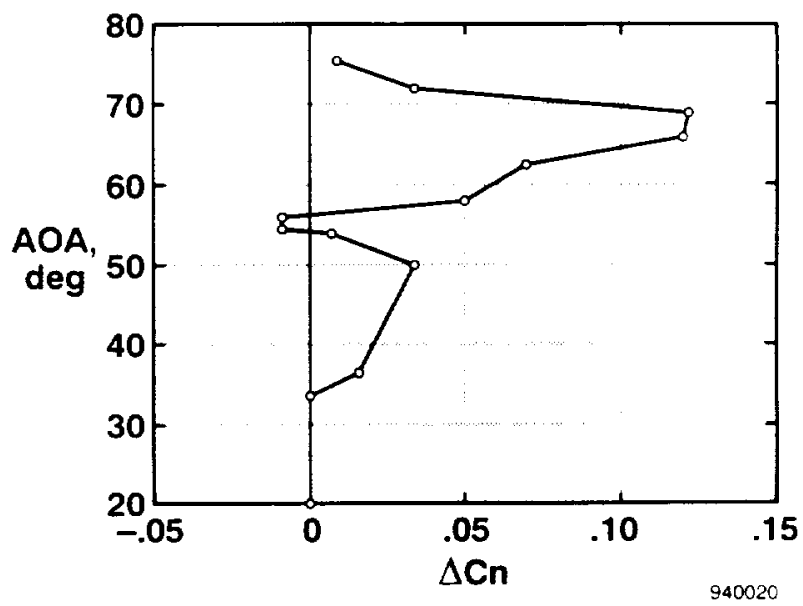

Fig. 22. Yawing moment asymmetry vs. AOA for the ship 2, flight 73 departure.

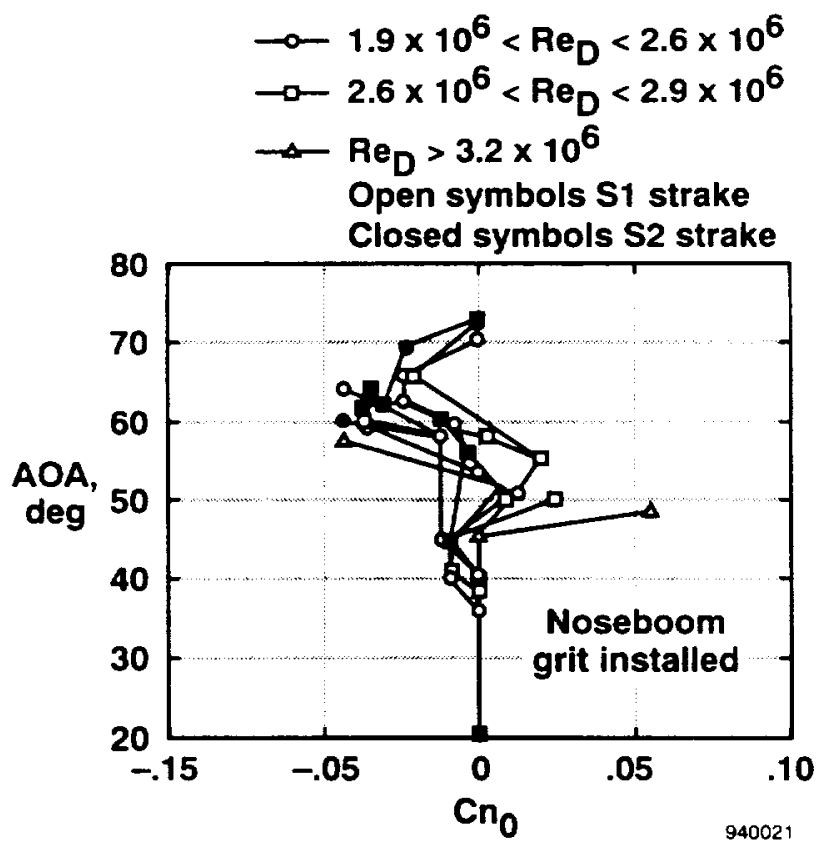

Fig. 23. Variation of yawing moment asymmetry with AOA for ship 2 dynamic maneuvers with the $\mathrm{S} 1$ strakes and noseboom transition strip. 


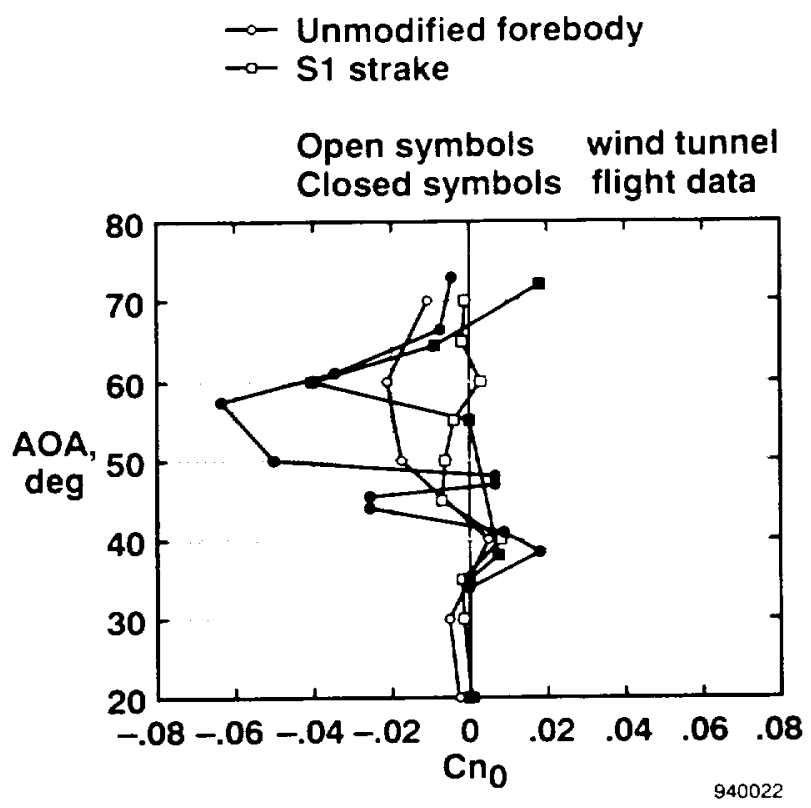

Fig. 24. Comparison of wind tunnel data to ship 1 flight results.

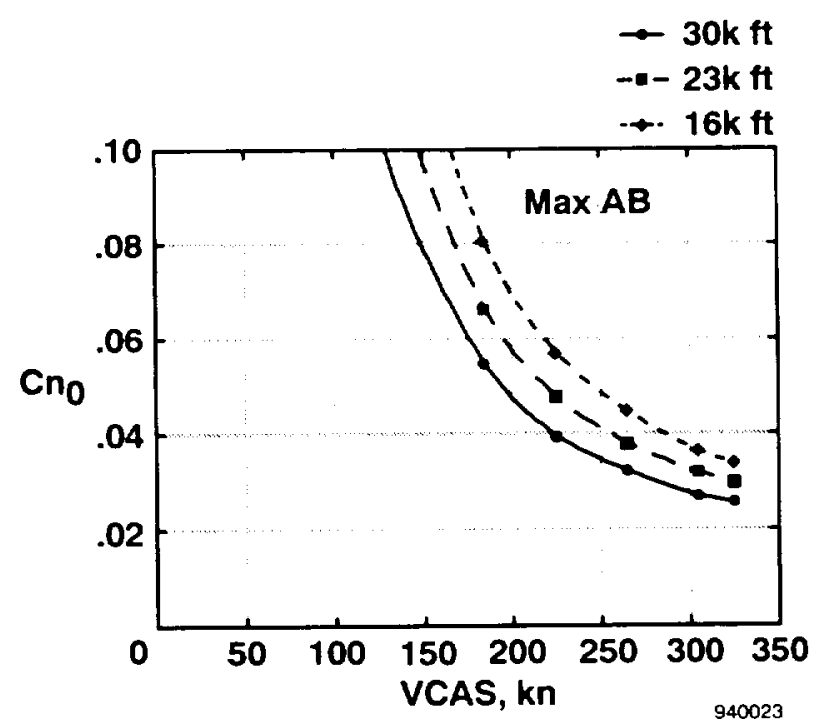

Fig. 25. Maximum yawing moment provided by thrust vectoring vs. calibrated airspeed. 

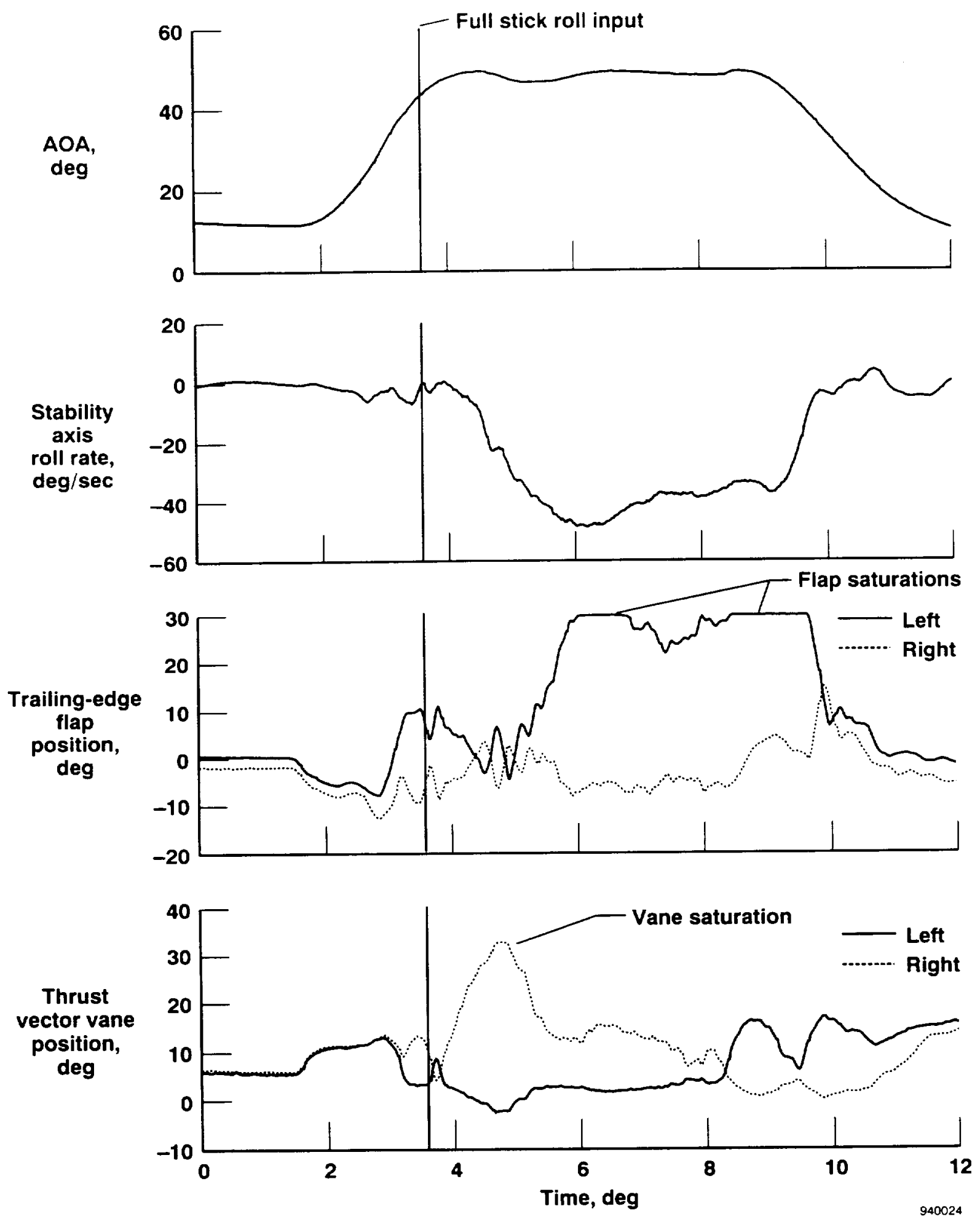

Fig. 26. Time history of a ship $2,50^{\circ} \mathrm{AOA}$ left rolling maneuver. 
Public reporting burden for this collection of information is estimated to average 1 houf per response, indudine the time tor reviewng instructions, searching existing data sources. gathering and maintaining the dal needed, and completing and reviewing the collection of intormation. Send comments regarding this burden estimate or any other aspect of this collection of intormation including suggestions tor reducing this burden, to Washington Headquartere Services, Directorate lop Information Operations and Reoorts, 1215 Jefferson Davis Highway. Sulte 1204, Aslinglon, VA 222024302, and to the Ottice of Management and Budget, Papenwork Reduction Project (0704-0188). Washington, DC 20503.

\begin{tabular}{|l|l|l|}
\hline 1. AGENCY USE ONLY (Leave blenk) & $\begin{array}{l}\text { 2. REPORT DATE } \\
\text { September } 1994\end{array}$ & $\begin{array}{l}\text { 3. REPORT TYPE AND DATES COVERED } \\
\text { Contractor RepOrt }\end{array}$ \\
\hline
\end{tabular}

4. TITLE AND SUBTTLE 5. FUNDING NUMBERS

High-Angle-of-Attack Yawing Moment Asymmetry of the X-31 Aircraft from Flight Test

6. AUTHOR(S)

RTOP 533-02

Brent R. Cobleigh (PRC Inc.)

7. PERFORMING ORGANIZATION NAME(S) AND ADDRESS(ES)

NASA Dryden Flight Research Center

P.O. Box 273 REPORT NUMBER

Edwards, Califomia 93523-0273

H-2015

9. SPONSORING/MONOTORING AGENCY NAME(S) AND ADDRESS(ES)

10. SPONSORING/MONITORING AGENCY REPOAT NUMBER

National Aeronautics and Space Administration

Washington, DC 20546-0001

NASA CR-186030

11. SUPPLEMENTARY NOTES

Presented as AIAA 94-1803 at the Applied Aerodynamics Conference, Colorado Springs, CO, June 20-23, 1994.

12a. DISTAIBUTION/AVAILABILTTY STATEMENT

12b. DISTRIBUTION CODE

Unclassified-Unlimited

Subject Category 05

\section{ABSTRACT (Maximum 200 worda)}

Significant yawing moment asymmetries were encountered during the high-angle-of-attack envelope expansion of the two X-31 aircraft. These asymmetries led to position saturations of the thrust vector vanes and trailing-edge flaps during some of the dynamic stability axis rolling maneuvers at high angles of attack. This slowed the high-angle-of-attack envelope expansion and resulted in maneuver restrictions. Several aerodynamic modifications were made to the X-31 forebody with the goal of minimizing the asymmetry. A method for determining the yawing moment asymmetry from flight data was developed and an analysis of the various configuration changes completed. The baseline aircraft were found to have significant asymmetries above $45^{\circ}$-angle of attack with the largest asymmetry typically occurring around $60^{\circ}$-angle of attack. Applying symmetrical boundarylayer transition strips along the forebody sides increased the magnitude of the asymmetry and widened the angle-of-attack range over which the largest asymmetry acted. Installing longitudinal forebody strakes and rounding the sharp nose of the aircraft caused the yawing moment asymmetry magnitude to be reduced. The transition strips and strakes made the asymmetry characteristic of the aircraft more repeatable than the clean forebody configuration. Although no geometric differences between the aircraft were known, ship 2 consistently had larger yawing moment asymmetries than ship 1.

14. SUBJECT TEAMS

Asymmetries; Forebody; High angle of attack; Noseboom; Reynolds number, Strakes; Tactical utility; Transition strips; X-31; Yawing moment

\begin{tabular}{|l|l|l|}
\hline $\begin{array}{l}\text { 17. SECUATY CLASSIFICATION } \\
\text { OF REPORT } \\
\text { Unclassified }\end{array}$ & $\begin{array}{l}\text { 18. SECURTYY CLASSIFICATION } \\
\text { OF THIS PAGE } \\
\text { Unclassified }\end{array}$ & $\begin{array}{l}\text { 19. SECUAITY CLASSIFICATION } \\
\text { OF ABSTRACT } \\
\text { Unclassified }\end{array}$ \\
\hline
\end{tabular}

NSN 7540-01-280-5500

\section{NUMBER OF PAGES} 34

16. PAICE CODE

$\mathrm{A03}$

20. LIMITATION OF ABSTRACT

Unlimited 